\title{
铁配合物催化的有机反应研究进展
}

\author{
何心伟* 胡小倩陶佳佳韩光商永嘉* \\ (安徽师范大学化学与材料科学学院 芜湖 241000)
}

\begin{abstract}
摘要 金属及其配合物催化的有机反应由于其快速、高效等优点成为近年来有机化学研究的热点, 铁配合物由于其催 化活性高、选择性好等优点受到化学家们的广泛关注. 综述了近年来发展的铁配合物催化的有机反应, 如聚合反应、 硅/硼氢化反应、环加成反应、氧化与还原反应、交叉偶联反应以及 $1,4-$ 加成反应等, 并对其发展前景进行了展望.

关键词 催化; 铁配合物; 有机反应; 研究进展
\end{abstract}

\section{Progress in Iron Complexes-Catalyzed Organic Reactions}

\author{
He, Xinwei* Hu, Xiaoqian Tao, Jiajia Han, Guang Shang, Yongjia* \\ (College of Chemistry and Materials Science, Anhui Normal University, Wuhu 241000)
}

\begin{abstract}
In recent years, metal and their complexes-catalyzed organic reactions have received much attention in organic chemistry due to their rapidity and efficiency. Iron complexes have attracted much attention from chemical society due to the advantages of high catalytic activity and selectivity. The advances of iron complexes-catalyzed organic reactions are reviewed, such as polymerisation reactions, hydrosilylation/hydroboration, cycloaddition, redox reactions, cross-coupling reactions and 1,4-additions, and the prospects of its development are forecasted.
\end{abstract}

Keywords catalysis; iron complexe; organic reaction; research progress

铁是地球上储量仅次于铝的元素之一(约 $4.7 \mathrm{wt} \%$ ), 原子量为 55.847 , 在元素周期表中位于第 VIII 族, 其电 子排布是 $[\mathrm{Ar}] 3 \mathrm{~d}^{6} 4 \mathrm{~s}^{2}$, 易失去 $4 \mathrm{~s}$ 轨道上的两个电子和 $3 \mathrm{~d}$ 轨道上的一个电子, 成为二价铁和半充满稳定结构的三 价铁离子，由于铁具有良好的可变氧化态，易于与氮、 氧、磷等元素配位形成稳定的配合物. 1949 年, Reppe ${ }^{[1]}$ 将五羰基配位的铁催化剂应用于烯烃的胺甲基化反应 而使得铁配合物催化剂成为有机化学研究工作者关注

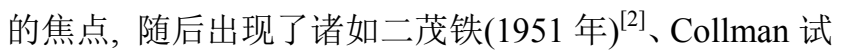
剂 $\mathrm{Na}_{2} \mathrm{Fe}(\mathrm{CO})_{4}$ (1959 年) $)^{[3]}$ 等关于铁配合物的研究. 此后 许多关于铁催化剂的设计合成及应用研究取得了系列 重要研究成果, 2004 年, Bolm 等 ${ }^{[4]}$ 综述了铁催化剂的重 要研究进展, 随后有关铁催化的有机反应的综述文章 ${ }^{[5]}$ 及专著 ${ }^{[6]}$ 相继出版. 本文综述了 2000 2015 年期间发展 的有关铁配合物催化剂类型及其催化的有机反应研究 方面所取得的进展.

\section{1 常见铁配合物催化剂类型}

近年来, 有关铁配合物的研究受到有机化学工作者 的广泛关注, 研究的热点集中在配体结构的设计合成及 其催化的有机反应等方面. 因此，设计合成结构新颖、 易配位的过渡金属配合物配体成为配位化学发展的热 点, 近年来发展的铁配合物类型主要有二茂铁及其金属 配合物 ${ }^{[7]}$ (图 1, A)、双齿配位铁配合物 ${ }^{[8]}$ (图 1, B, 如 $N, N-$ 双齿)、三齿铁配合物 ${ }^{[9]}$ (图 1, C, 如吡啶双亚胺 $N, N, N-$ 三齿、吡啶双吡咯 $N, N, N$-三齿、吡啶双亚磷 $P, N, P$-三齿 以及 $S, N, S$-三齿铁配合物等)、四齿配位铁配合物 ${ }^{[10]}$ (图 $1, \mathbf{D}$, 如 $P, N, N, P$-四齿、 $N, N, N, N$-四齿)、N-杂环卡宾 (NHC) 铁配合物 ${ }^{[11]}$ 及其他结构新颖的铁配合物(图 1, E).

多数铁配合物由于合成简便, 易与含 $O, N, P$ 等配位 原子的配体配位而形成稳定的配合物及具有高催化

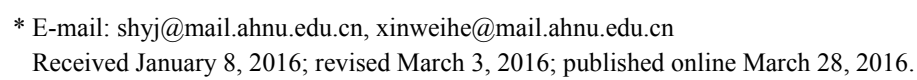

Project supported by the National Natural Science Foundation of China (Nos. 21172001, 21372008) and the Natural Science Foundation of Anhui Province (No. 1308085QB39) and the Doctoral Scientific Research Foundation of Anhui Normal University (No. 2016XJJ110).

国家自然科学基金(Nos. 21172001, 21372008)、安徽省自然科学基金(No. 1308085QB39)及安徽师范大学博士科研启动基金(No. 2016XJJ110)资助项目. 


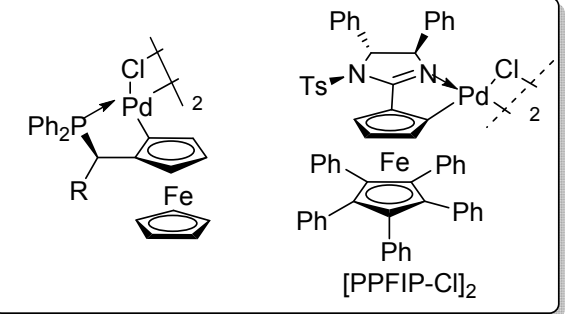

A: Ferrocene-based metal complexes

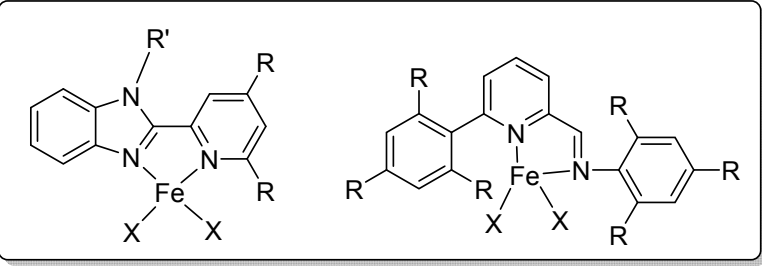

B: $N, N$-Bidentate iron complexes<smiles>[R]c1cc([R])c(N2C(C)=C(C)N(c3c([R])cc([R])cc3[R])C(C(C)(C)Cl)=C2C)c([R])c1</smiles>

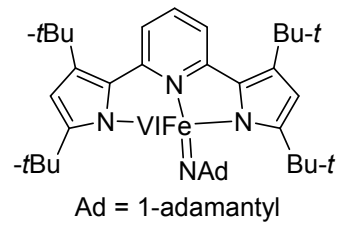

$\mathrm{Ad}=1$-adamantyl

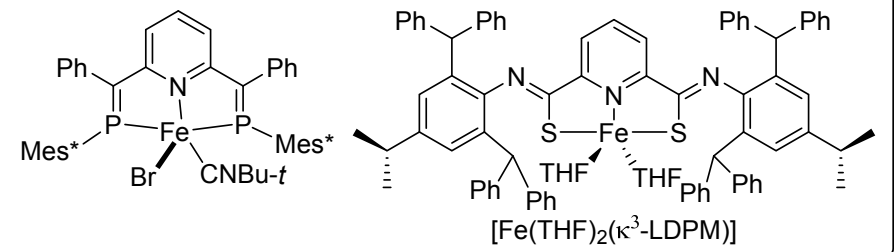

C: $N, N, N-, P, N, P-, S, N, S$-tridentate iron complexes

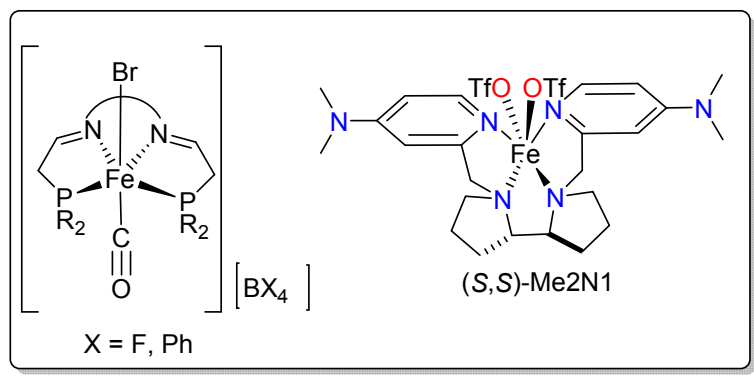

D: $P, N, N, P-, N, N, N, N$-tetradentate iron complexes

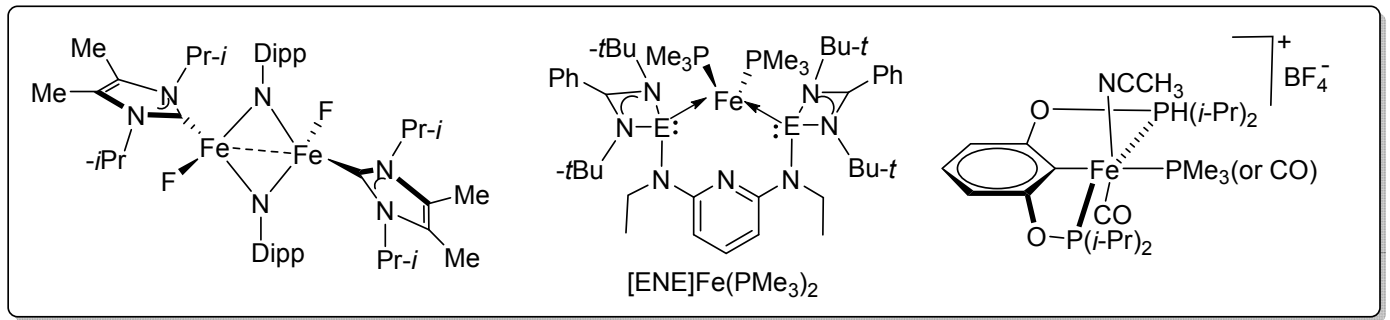

E: Other iron complexes

图 1 常见的铁配合物催化剂类型

Figure 1 Type of iron complexe catalysts

活性、高选择性等优点在有机合成中有着广泛的应用， 如催化聚合反应、硅/嘲氢化反应、环加成反应、氧化与 还原反应、交叉偶联反应以及 1,4 -加成反应等.

\section{2 聚合反应}

近年来, 聚乙烯、聚丙烯、聚苯乙烯等传统的烯烃 聚合物及其与环烯烃、极性分子的共聚体在科学界和工 业界备受关注. 一方面, 大量聚烯烃已成为商品, 深入 到人们生活的方方面面; 另一方面, 许多具有新型功能 的聚合物不断涌现, 并成为潜在的现有产品的替代品或 全新的功能材料. 烯烃在催化剂的作用下, 转变成聚烯 烃, 并随着催化剂结构的变化, 聚烯烃产物的性能也不 断改变, 因此催化剂是研究聚烯烃材料的核心和原动 力. 有机金属烯烃聚合物催化剂的出现不仅可以在温和
的反应条件下得到用传统方法通常要在高温高压或自 由基引发等苛刻条件下方可实现的烯烃聚合，而且这些 新型催化剂可以剪裁聚合物的微结构, 实现聚合物物理 性质的调控, 使得化学家、材料学家可以在分子水平上 设计新型功能聚烯烃材料和改善已有聚合物的性能.

\section{1 炔烃聚合}

2011 年, McGuinness 等 ${ }^{[12]}$ 首次将一种 2,6-二芳亚氨 基吡啶铁(II)配合物 1 作为催化剂应用于乙炔聚合反应 (Eq. 1), 研究结果表明, 该类催化剂催化活性极高, 催 化剂用量较传统催化剂可降低三个数量级, 且在较低的 催化剂用量下催化乙炔聚合反应在催化剂表面可以得 到乙炔聚合物膜. 但是该类铁配合物催化剂虽能很好地 催化乙炔的聚合反应，却无法实现对聚合物链的控制合 成, 有望通过对配体结构的进一步修饰来完成. 


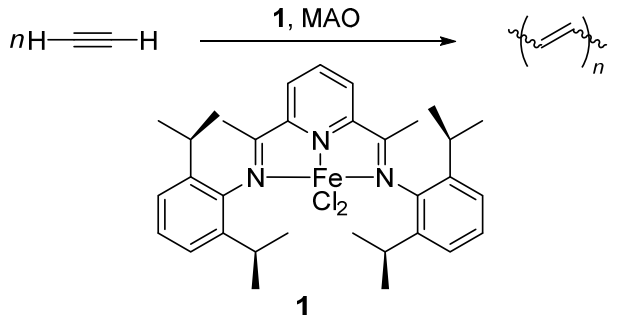

\section{2 烯烃聚合}

2013 年, Sun 等 ${ }^{[13]}$ 设计合成并表征了一种双吡啶双 亚胺铁配合物催化剂 2 , 并将该配合物催化剂应用于催 化烯烃聚合反应(Scheme 1). 结果发现, 该类催化剂具 有较高的催化活性, 在甲基铝氧烷(MAO)或改良的甲基 铝氧烷 (MMAO) 共催化作用下, 其催化活性可高达 $1.3 \times 10^{7} \mathrm{~g} \cdot \mathrm{mol}^{-1}(\mathrm{Fe}) \cdot \mathrm{h}^{-1}$, 与类似单金属和其他双核金 属配合物催化剂相比, 该双金属催化剂具有很高的热稳 定性, 在 $70{ }^{\circ} \mathrm{C}$ 高温下同样具有较高的催化活性, 且催 化剂寿命也得到相应提高, 运用该系列催化剂催化乙烯 聚合时, 乙烯聚合度较高, 聚合后的聚乙烯材料的分子 量可达到 $383 \mathrm{~kg} / \mathrm{mol}\left(M_{\mathrm{w}}\right)$. 该类铁配合物催化剂合成方 法简便，在工业上具有潜在的应用前景.<smiles>[R]c1cc(-c2cc([R])c(N)c([18OH])c2)cc([12H])c1N</smiles><smiles>[Y]N=C(C)c1cccc(C(C)=Nc2c([R])cc(-c3cc([R])c(N=C(C)c4cc(C)cc(C(C)=NN)n4)c([R])c3)cc2[R])n1</smiles>

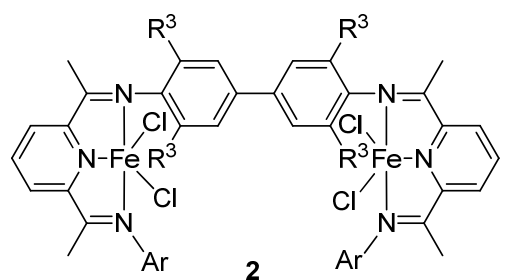

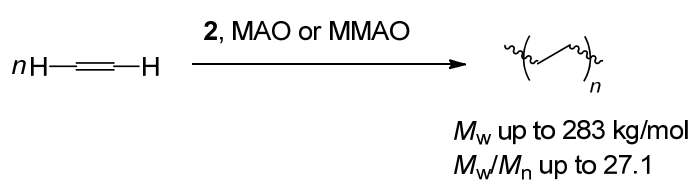

图式 1 双吡啶双亚胺铁配合物的合成及其催化烯烃聚合反 应

Scheme 1 Synthesis of bispyridine-bisimino iron complexes and catalysis of olefin polymerization
2014 年, Sun 等 ${ }^{[14]}$ 设计合成了系列 2-(1-芳亚胺基)乙基-9-芳亚胺基-5,6,7,8-四氢环庚烷并吡啶配体 (Scheme 2), 并与氯化亚铁进行反应合成得到系列相应 的 $\mathrm{Fe}(\mathrm{II})$ 配合物 $\mathbf{3 a} \sim \mathbf{3 e}$, 配合物单晶结构和密度泛函 (DFT)理论计算证实，该配合物中心原子铁周围的配体 形状为扭曲的双雉体几何形状. 该类配合物作为催化剂 在乙烯聚合反应中，显示了更高的催化活性(高达

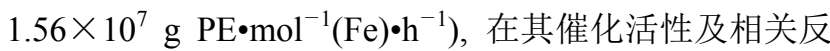
应参数的研究中发现配体中环庚烷的环张力对其催化 活性有较大影响. 利用该类铁配合物催化的乙烯聚合反 应，可通过控制实验参数来得到不同分子量和分散性的 聚乙烯产品，从而使得该配合物催化剂有望在工业上实 现大规模应用.

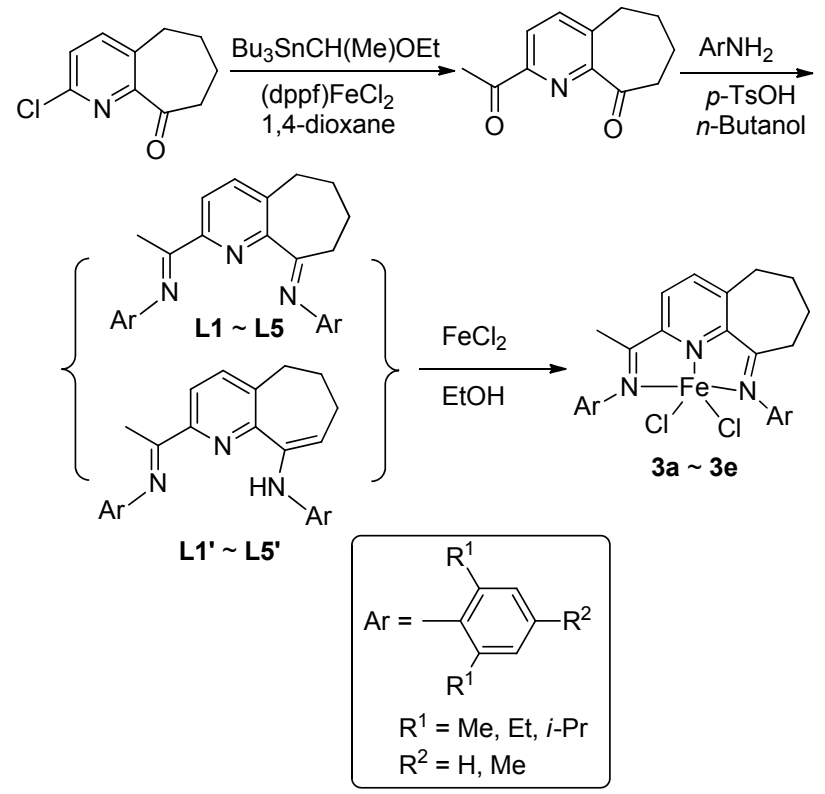

图式 2 吡啶双亚胺铁配合物的设计合成

Scheme 2 Synthesis of bisnminopyridine iron complexes

\section{3 硅/硼氢化反应}

不对称硅/坧氢化反应可用于合成手性醇、胺、硅烷 等手性化合物，自从 20 世纪 70 年代初发现以来, 有关 前手性酮、烯烃、亚胺等底物催化不对称硅氢化反应的 研究报道呈现出两个研究高峰. 第一个研究高潮出现于 20 世纪 20 年代中期至 80 年代初, 研究重点侧重于各种 反应底物, 手性催化剂的开发研究报道不多, 主要是采 用其他催化不对称反应如不对称加氢、氢甲酰化反应中 常用的手性催化剂. 第二个研究高潮出现于 20 世纪 90 年代初, 至今方兴未艾, 研究重点侧重于各种高效手性 催化剂配体的合成，在酮、烯烃和亚胺等的不对称硅/ 硼氢化反应研究中均合成出了多种具有高活性、高手性 诱导效应的手性配体. 


\section{1 烯烃的不对称硅/硼氢化反应}

烯烃类化合物不对称硅/嗍氢化反应是最早被研究 的, 一般是经硅/硼氢化反应以后, 用双氧水进行氧化处 理, 可得到手性醇. 由于其反应比较复杂, 立体选择性 和位置选择性要兼顾, 增加了研究的困难性, 同样是到 了 20 世纪 90 年代后, 找到了高效的手性催化剂, 尤其 是含有手性轴的联菜类配体的发现和应用, 才真正使烯 烃的不对称硅/硼氢化反应研究取得了突破性进展, 并 重新受到重视. 近年来铁配合物催化剂的合成及应用得 到快速发展，由于其易于合成，催化活性和选择性高， 研究工作者逐渐将铁配合物催化剂应用于烯烃的不对 称硅/䃉氢化反应中, 并且取得了良好催化效果.

\section{1 .1 烯烃的不对称硼氢化反应}

2014 年, $\mathrm{Lu}$ 等 ${ }^{[15]}$ 设计合成了一种手性噁唑啉吡啶 双亚胺铁(II)配合物 4, 并将其应用于 1,1-二取代烯烃的 反马氏硼氢化反应(Scheme 3). 结果表明, 该催化剂催 化的烯烃嗍氢化反应具有较高的区域选择性和对映选 择性, 配体中的吡啶亚胺基团可以稳定铁的配位, 利用 手性惡唑啉基团控制烯烃嗍氢化反应的对映选择性. 该 催化剂具有良好的反应性能和稳定性, 可实现温和条件 下系列手性含硼衍生物的高效合成, 但是反应仍存在以 下局限性, 如只适用于 $\alpha$-位取代的苯乙烯衍生物, 当苯
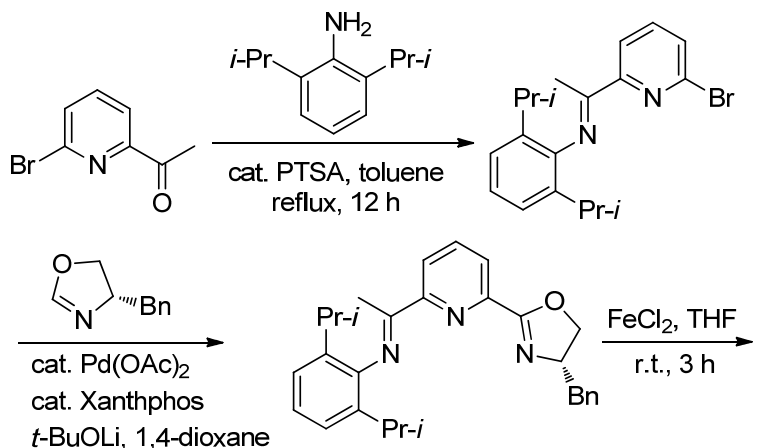

t-BuOLi, 1,4-dioxane

$100^{\circ} \mathrm{C}, 12 \mathrm{~h}$
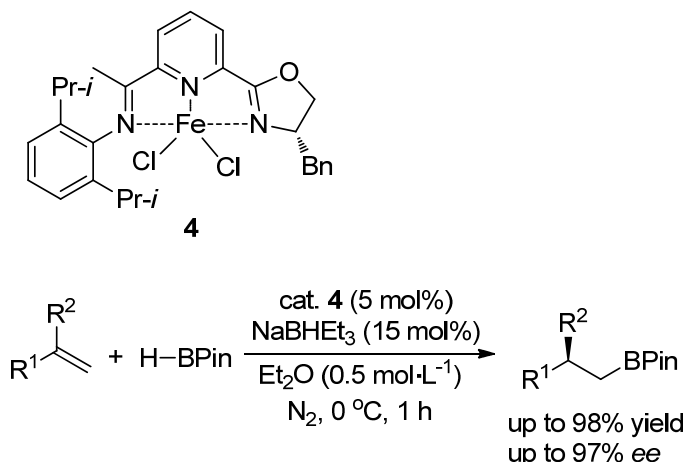

图式 3 手性噁唑啉基吡啶双亚胺铁配合物的设计合成及其 催化活性

Scheme 3 Synehtsis of chiral iminopyridine oxazoline iron complexes and catalytic activity
环上连有强吸电子基或 $\alpha$-位连有位阻较大的基团时, 反应的对映选择性虽能得到保持，但产率却出现明 显下降等.

\section{1 .2 烯烃的不对称硅氢化反应}

2015 年, $\mathrm{Lu}$ 等 ${ }^{[16]}$ 将上述配合物的配体进行了结构 修饰，合成了几种新型惡唑啉吡啶亚胺铁(II)配合物 $\mathbf{5 a} \sim 5 \mathbf{e}$, 将其应用于烯烃的反马氏加成硅氢化反应(Eq. $2)$, 以良好区域选择性和对映选择性( ee $>99 \%)$ 合成得 到系列手性硅烷的衍生物. 该类铁配合物催化剂消除了 对底物取代基电子效应和空间效应的影响，即使 $\alpha$-位取 代的芳基乙烯苯环上连有强吸电子的三氟甲基或 $\alpha$-位 连有较大位阻的叔丁基时，产率仍能保持在 $95 \%$ 以上， 且产物的 $e e$ 值也可达到 $99 \%$. 同时通过偶联环化、氧化 开环和分子内 Mitsunobu 反应等实现了烯烃硅氢化产物 在(一)-thespesone 和 $(S)-(+)-3$-methyl dihydrobenzofuran 等天然产物合成中的应用.

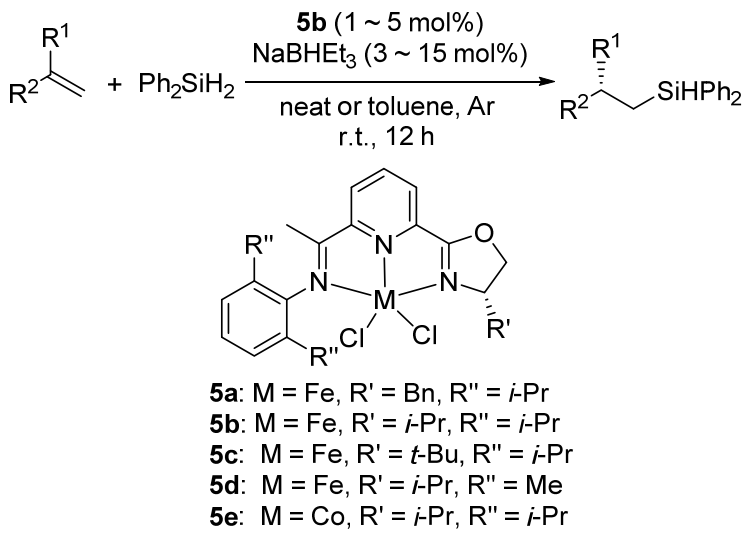

\section{2 酮的硅氢化反应}

酮类化合物的不对称硅氢化反应研究最早，也最为 系统. 近年来不断有高效手性配体或催化剂的研究报道 出现, 有的已达到几乎定量的化学产率和光学纯度 ${ }^{[17]}$. 2014 年, Driess 等 ${ }^{[11 b]}$ 报道了一种新颖的双金属烯基吡啶 钳形(ENE)铁配合物 6 的合成及其催化苯乙酮的硅氢化 反应研究. 首先从 2,6 -二乙胺基吡啶出发, 分别与 2 equiv. 的正丁基锂和 $N, N^{\prime}$-二叔丁基苯甲脒基氯硅烯或 $N, N^{\prime}$-二叔丁基苯甲脒基氯锗烯反应得到相应的 $\mathrm{SiNSi}$ 型 或 GeNGe 型配体，该配体室温下与 1.1 equiv.的氯化亚 铁作用四氢呋喃溶剂中反应 $3 \mathrm{~h}$ 即可得到相应的钳形铁 配合物 $[\mathrm{SiNSi}] \mathrm{FeCl}_{2}$, 然后在 $\mathrm{PMe}_{3}$ 作用下与 $\mathrm{KC}_{8}$ 反应可 以得到一种富电子的 $\mathrm{Fe}(0)$ 配合物 $[\mathrm{SiNSi}] \mathrm{Fe}\left(\mathrm{PMe}_{3}\right)_{2}$. 配 合物 $[\mathrm{SiNSi}] \mathrm{Fe}\left(\mathrm{PMe}_{3}\right)_{2}$ 在苯乙酮的硅氢化还原反应中表 现出良好的催化活性(Eq. 3), 结果发现，底物取代基的 电子效应对反应的影响不大，无论是含有强供电子基或 强吸电子基的对位取代苯乙酮，均能以优异的产率获得 相应的 $\alpha$-苯乙醇产物, 但是底物的普适性和催化剂的催 
化作用机理仍需进一步探索, 以找到底物取代基效应的 一般规律和配合物在羰基的硅氢化反应过程中的作用.

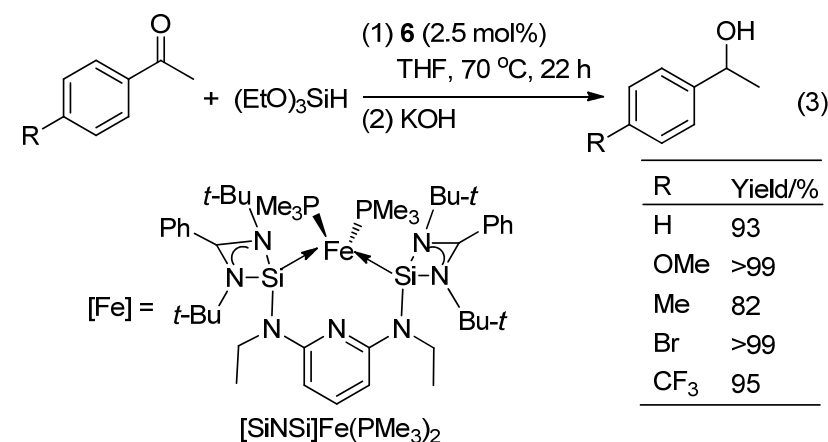
6

2014 年, Guan 等 ${ }^{[18]}$ 报道了一种 POCOP 钳形阳离子 铁配合物 $\left\{\left[2,6-\left(i-\mathrm{Pr}_{2} \mathrm{PO}\right)_{2} \mathrm{C}_{6} \mathrm{H}_{3}\right] \mathrm{Fe}(\mathrm{CO})\left(\mathrm{PMe}_{3}\right)\left(\mathrm{CH}_{3} \mathrm{CN}\right)\right\}^{+}$ $\left[\mathrm{BF}_{4}\right]^{-}\left(7,[\mathrm{Fe}]^{+}-\mathrm{BF}_{4}^{-}\right.$, trans $\left.\mathrm{CO} / \mathrm{CH}_{3} \mathrm{CN}\right)$ 在催化醛酮的硅 氢化反应中的应用(Eq. 4), 该配合物催化剂在 $1 \mathrm{~mol} \%$ 的 用量下即可实现苯甲醛的定量转化, 该工作首次实现了 阳离子型铁配合物催化剂在醛酮的硅氢化反应中的应 用.

$$
\mathrm{R}_{\mathrm{R}^{\prime}} \stackrel{\text { cat. } 7(1 \mathrm{~mol} \%)}{\mathrm{C}_{6} \mathrm{H}_{5} \mathrm{Cl}}
$$

2015 年, Huang 等 ${ }^{[19]}$ 设计合成了一种新颖的手性噁 唑啉吡啶亚胺配体(IPO ligands), 该配体中含有两个二 苯甲基和一个叔丁基等三个具有较大位阻的取代基，与 $\mathrm{FeBr}_{2}$ 进行配位得到一种相应的铁 (II) 配合物 $(S)-\mathbf{8}$ (Scheme 4), 并将其应用于芳基酮的不对称硅氢化反应. 由于配体中的大位阻作用而使得该铁配合物具有较高 的催化活性 (>99\%) 和对映选择性 $(e e>93 \%)$. 结果发 现，该催化剂对各种取代基的芳基乙酮或脂肪族酮均有 良好的催化效果, 均能以优异产率获得相应的醇产物, 但是对脂肪族酮或二苯甲酮的催化对映选择性较差, 因 此需通过进一步修饰配体的空间位阻来提高其催化脂 肪族酮硅氢化反应的对映选择性.

2015 年, Gade 等 ${ }^{[20]}$ 设计合成了一种含双啞唑啉配 体的铁烷基配合物 9 和铁烷氧基配合物 10, 将其应用于 催化烷基酮和芳基酮的不对称硅氢化反应(Scheme 5). 结果发现, 该类催化剂具有很高的催化活性和对映选择 性 $\left(\mathrm{TOF}=240 \mathrm{~h}^{-1},-40{ }^{\circ} \mathrm{C}, e e>99 \%\right)$. 该配合物催化
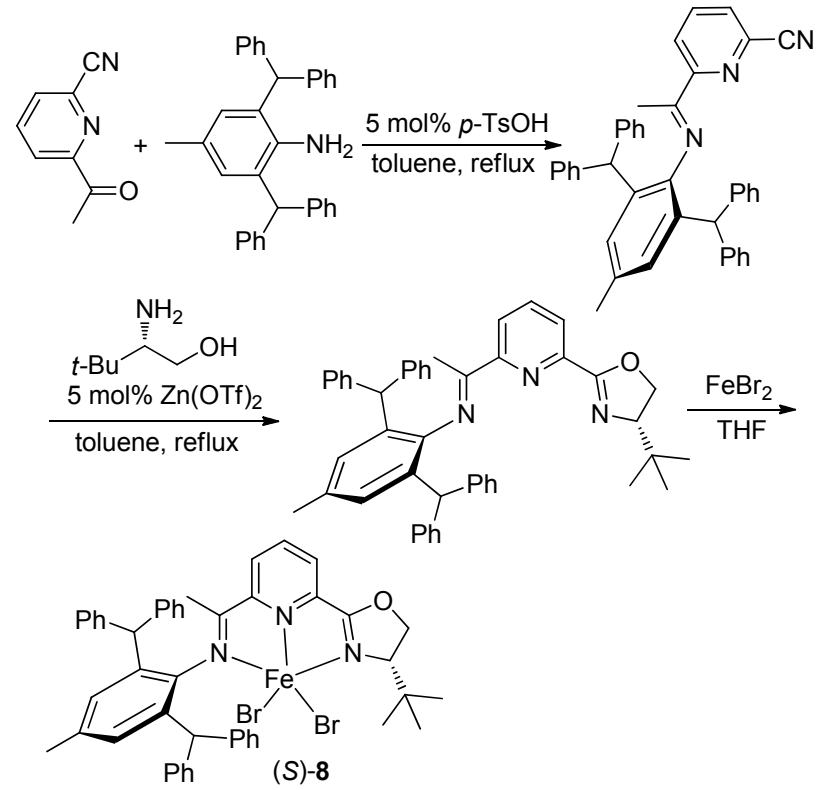

(1) $1 \mathrm{~mol} \%(S)-8$

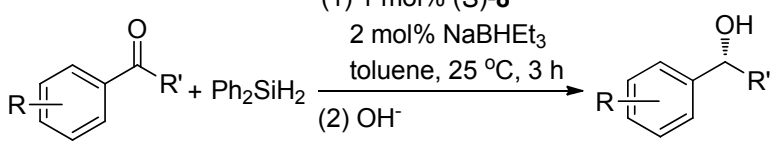

图式 4 手性噁唑啉基吡啶亚胺铁配合物的设计合成及其催 化活性

Scheme 4 Synehtsis of iminopyridine-oxazoline iron complexes and their catalytic activity

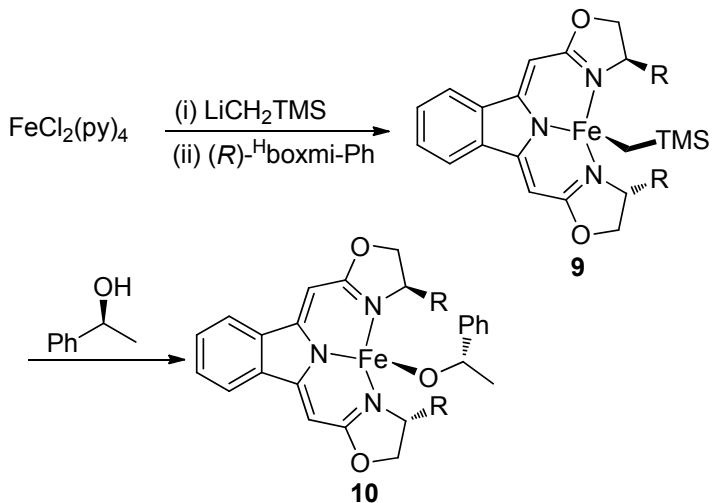

(a) cat. 10 (5 mol\%)

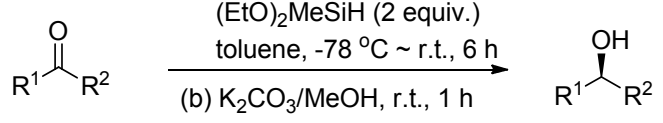

$$
\begin{aligned}
& >95 \% \text { yield } \\
& \text { up to } 99 \% \text { ee }
\end{aligned}
$$

图式 5 手性双啞唑啉基烷氧基铁配合物的设计合成及其催 化活性

Scheme 5 Synthesis of bisoxazoline-alkoxido iron complexes and their catalytic activity

剂对底物的适用范围很广, 即使底物酮中含有较大位阻 的取代基时也可以高于 $95 \%$ 的产率得到相应高 $e e$ 值的 手性产物，当底物酮中不含长链烷基时，催化的对映选 择性更高 $(e e>99 \%)$. 该配合物中配体结构的进一步修 
饰及其催化机理的研究尚在继续中.

2015 年, Nishiyama 等 ${ }^{[21]}$ 以手性和非手性的双啞唑 啉三甲基硅基或锡基苯配体 11 (abbreviated as phebox) 与 $\mathrm{Fe}(\mathrm{CO})_{5}$ 在光照条件下氧化加成反应得到系列 $\mathrm{NCN}$ 型钳形铁配合物 [(phebox) $\left.\mathrm{Fe}(\mathrm{CO})_{2}\left(\mathrm{MMe}_{3}\right)\right](\mathbf{1 2})$, 其中 $\mathrm{M}$ 为 $\mathrm{Si}$ 或 $\mathrm{Sn}$, 随后将该系列铁配合物应用于苯乙酮的不对 称硅氢化反应中(Scheme 6), 结果表明, 系列配合物中 $M$ 为 $\mathrm{Si}$ 的配合物的催化活性最高(产率 $>99 \%$ ), 遗憾的是 该类配合物催化苯乙酮的硅氢化反应的对映选择性不高 $(e e>34 \%)$. 为进一步提高该类配合物的催化对映选择 性，该课题组在对配体的结构作进一步的修饰研究.
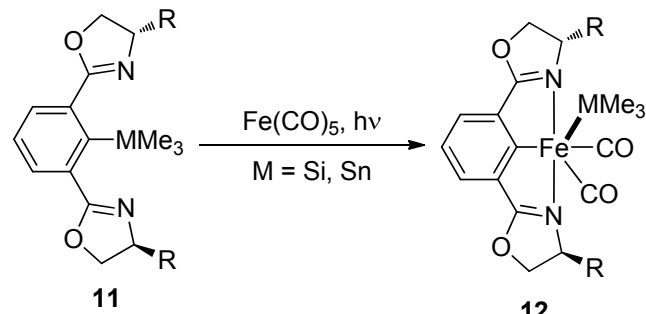

(1) $12(2 \mathrm{~mol} \%)$

12

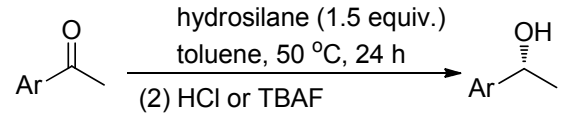

图式 $6 \mathrm{NCN}$ 钳形铁配合物的设计合成及其催化活性

Scheme 6 Synthesis of NCN pincer iron complexes and their catalytic activity

近年来, 一类自身携带氢的铁配合物催化剂受到关 注，此类催化剂将金属本身配位的氢作为硅氢化反应的 氢源来完成还原反应. 2014 年, $\mathrm{Li}$ 等 ${ }^{[22]}$ 利用二苯甲酮亚 胺配体与 $\mathrm{Fe}\left(\mathrm{PMe}_{3}\right)_{4}$ 或 $\mathrm{FeMe}_{2}\left(\mathrm{PMe}_{3}\right)_{4}$ 配位得到四种含氢 铁的配合物 $13 \mathrm{a} \sim 13 \mathrm{~d}$, 随后将该铁配合物应用于催化 醛酮的硅氢化反应. 结果表明, 该类铁配合物催化剂对 醛酮的硅氢化反应具有良好的催化活性, 四种配合物催 化剂相比较而言, 配合物 13a 的催化效果最好, 并对该 类配合物的催化硅氢化反应的催化循环提出了一种可 能的反应机理(Scheme 7). 提出的机理指出, 含氢铁配 合物催化剂 13 首先会脱去一个 $\mathrm{PMe}_{3}$ 配体形成具有催化 活性的不饱和中间体 $\mathbf{A}$, 继而酮羰基与中心原子铁进行 配位得到中间体 $\mathbf{B}$, 进一步发生氢转移而转化为不饱和 配合物中间体 $\mathbf{C}$, 最后是硅烷还原酮生成硅醚产物并释 放中间体 $\mathbf{A}$ 完成催化循环.

$\mathrm{Li}$ 和 Sun 等 ${ }^{[23]}$ 利用 $\mathrm{C}_{\mathrm{sp}^{3}}-\mathrm{H}$ 键和 $\mathrm{Si}-\mathrm{H}$ 键活化设计 合成了一类新颖的 PXP $(X=C, S i)$ 钳形含氢铁配合物催 化剂 14 和 15, 并将其应用于醛酮的不对称硅氢化反应 中(Eq. 5), 结果显示该类催化剂在醛酮的不对称硅氢化 反应中显示了优异的催化活性，催化剂用量降低至 0.3 $\mathrm{mol} \%$ 时仍有良好的催化活性, 且催化底物的适用范围

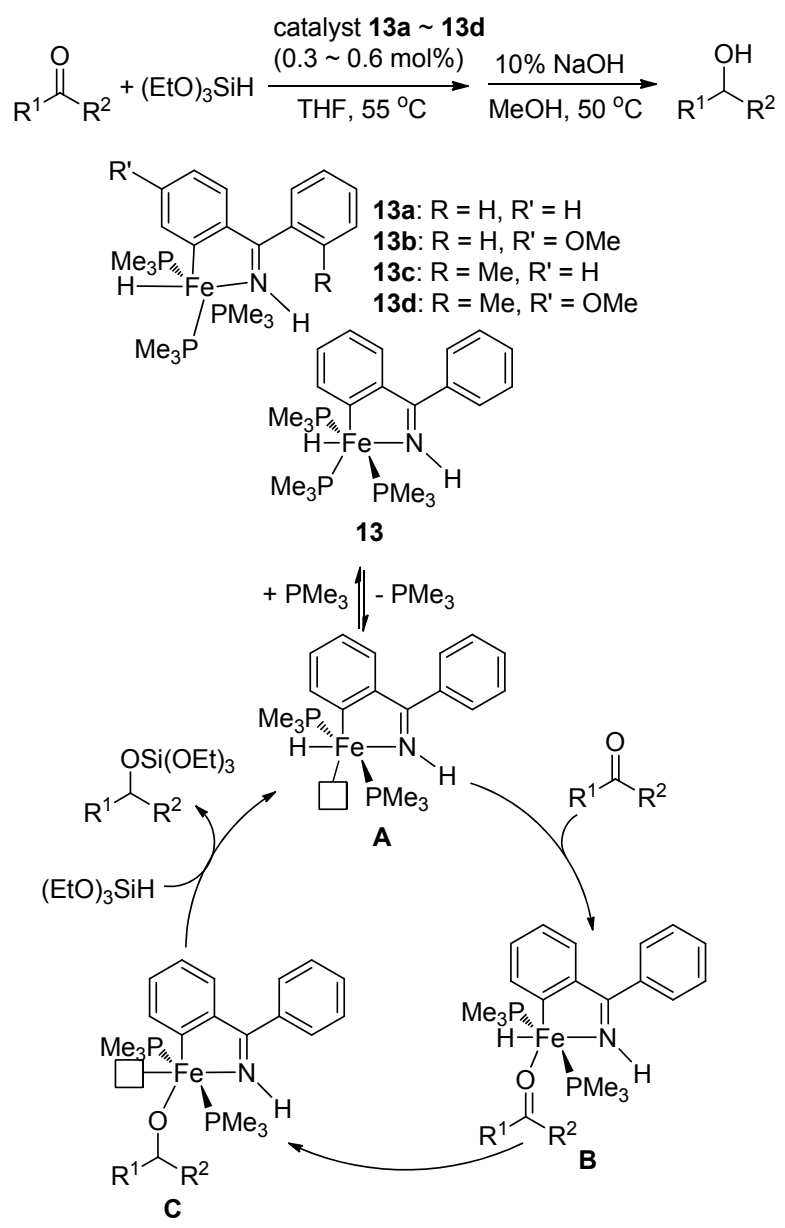

图式 7 含氢铁配合物催化剂催化酮的硅氢化反应及其机理 Scheme 7 Mechanism of catalytic hydrosilylation with hydrido iron complexes

很广，各种类型的醛(芳醛、杂芳醛、苄基醛)和酮(芳基 酮、杂芳基酮、二苯甲酮、环烷酮)均能很好地应用该 类催化剂进行硅氢化还原得到相应的醇类化合物，但是 当芳醛对位连有强供电子基(如甲氧基)时，仅能以中等 左右收率得到目标产物，而使用二苯甲酮作底物时其反 应性较差，产率仅有 $21 \%$ 。因该类催化剂的合成条件温 和、实验操作简单使得其具有有潜在的应用价值和广泛 的应用前景.

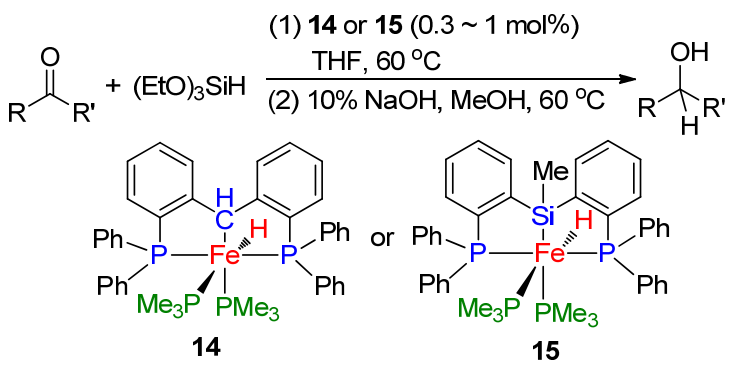

2015 年, Sun 等 ${ }^{[24]}$ 又用类似的方法合成得到一种与 上述配合物结构相似的 POCOP 钳形含氢铁配合物催化 
剂 16 (Eq. 6), 该类催化剂较上述催化剂的优点在于其 催化活性更高, 使用相同量的催化剂催化各种芳香醛或 杂芳香醛时均能以优异收率得到相应的醇类化合物, 基 本不受芳环上取代基电子效应和空间效应的影响. 该催 化剂虽也能很好地催化芳基酮的硅氢化反应，但其催化 产率普遍偏低, 仅有催化二苯甲酮和环己酮的硅氢化反 应的分离产率有所提高. 由此可见, 延长钳形铁配合物 的钳形链长可提高其催化活性和催化选择性, 但是合成 该类铁配合物催化剂的时间较长 $\left(0{ }^{\circ} \mathrm{C}\right.$ 下反应 $\left.3 \mathrm{~d}\right)$, 因此 需要发展更为简单高效的合成方法来进一步扩大该类 铁配合物催化剂的在有机反应中的实际应用.

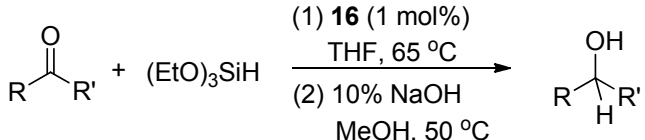

$$
\begin{aligned}
& \text { Bu-t }
\end{aligned}
$$

随后, $\mathrm{Li}$ 等 ${ }^{[25]}$ 利用选择性 $\mathrm{C}-\mathrm{F} / \mathrm{C}-\mathrm{H}$ 键活化的方法 合成得到两种含氟二芳基甲亚胺的含氢铁配合物 17 , 该配合物在醛酮的硅氢化还原反应中显示了更加优异 的催化活性，不仅降低了反应的时间，而且大大提高了 反应的转化率和产物的分离收率. 研究发现, 底物适用 范围很广, 各种取代基的芳香醛和芳香酮都能获得优异 的收率, 即使脂肪族的环己酮和环戊酩也有中等以上收 率. 研究中还发现, 随着催化剂用量的减少, 该种含氢 铁配合物催化剂对芳香醛和芳香酮的硅氢化反应中表 现出良好的化学选择性, 当催化剂用量降低至 $0.3 \mathrm{~mol} \%$ 时可选择性还原芳香醛(Eq. 7), 而芳香酮不被还原.

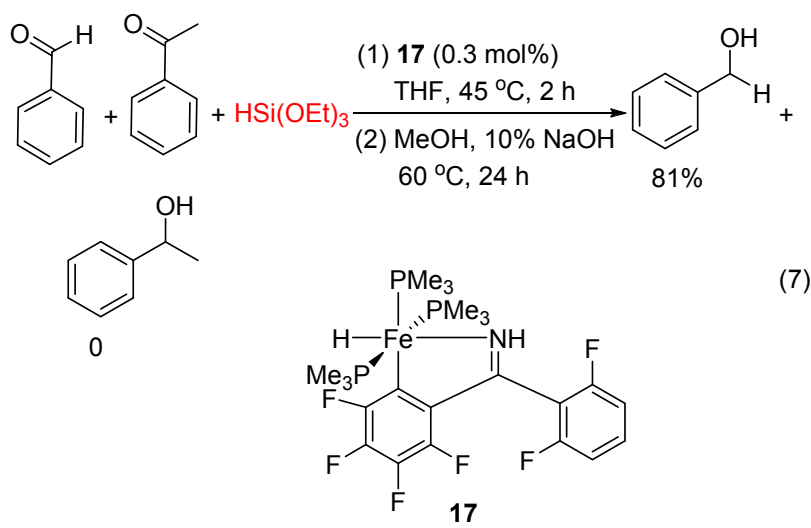

为进一步研究底物的适用范围, 他们用该配合物测 试了对 $\alpha, \beta$-不饱和醛的硅氢化还原反应(Eq. 8), 在相同
条件下也显示良好的催化活性, 且当 $\alpha, \beta$-不饱和醛的 $\alpha$ 位连有取代基时，其反应效果较好，产率可高达 93\%。 即使使用 3-苯基丙炔醇作为反应底物时也能以 $88 \%$ 产 率获得相应的产物.

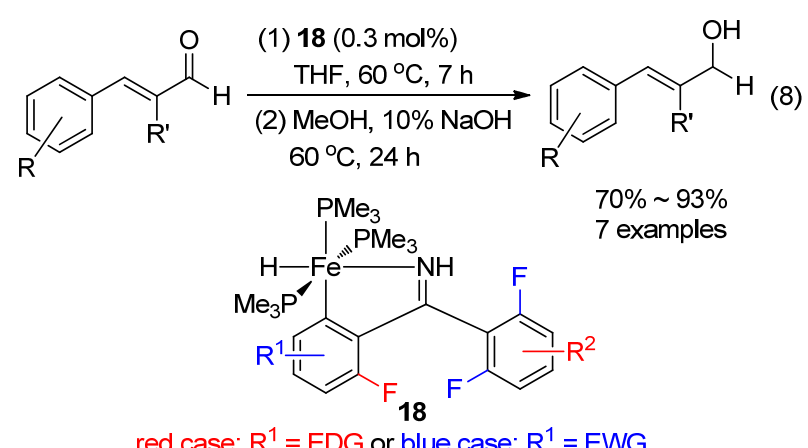

近期, 该课题组 ${ }^{[26]}$ 设计合成了一种 $P, S$-螯合的含氢 铁(II)配合物 19, 并将其应用于醛酮的硅氢化还原反应 中(Eq. 9), 结果发现，该类配合物具有良好的催化活性， 对苯环上连有供电子的芳香醛时其反应性较差，但对二 苯甲酮的硅氢化反应较之前的 $\mathrm{PC}(\mathrm{Si}) \mathrm{P}$ 钳形或 POCOP 钳形铁配合物催化剂催化活性有较大提高.

$$
\underset{\mathrm{R}^{\prime}}{\stackrel{\text { (1) } 19(2 \mathrm{~mol} \%), \mathrm{THF}}{(2) 10 \% \mathrm{NaOH}, \mathrm{MeOH}}}
$$

\section{4 环加成反应}

\section{1 不对称[3+2]环加成反应}

二茂铁是最早发现的铁的配合物, 其衍生物此后一 直作为配合物催化剂或金属配体使用，并得到快速发展. 近年来基于二茂铁衍生物为配体的不对称催化反应受到 有机化学家的广泛关注. 2010 年, $\mathrm{Hu}$ 等 ${ }^{[27]}$ 以 $N, N$-二甲基$(R)$-1-(S)-2-二苯基膦基二茂铁乙胺为原料合成得到系列 二茂铁基 $P, S$-配体 20 , 随后将该配体与 $\left[\mathrm{Cu}\left(\mathrm{CH}_{3} \mathrm{CN}\right)_{4}\right]-$ $\mathrm{ClO}_{4}$ 或 $\mathrm{AgOAc}$ 一起作为催化剂催化亚氨基酯和 2-环戊 烯酮或查尔酮的 $[3+2]$ 环加成反应(Scheme 8). 结果表明, 应用 $\left[\mathrm{Cu}\left(\mathrm{CH}_{3} \mathrm{CN}\right)_{4}\right] \mathrm{ClO}_{4} /\left(R_{\mathrm{c}}, S_{\mathrm{Fc}}\right)-20 \mathrm{f}$ 催化体系催化 2-环戊 烯酮与亚氨基酯的 [3+2]环加成反应时，以近乎完美的 对映选择性 $(>99 \% e e)$ 得到唯一 $\mathrm{endo}$ - 型加成产物, 而应 用 $\mathrm{AgOAc} /\left(R_{\mathrm{c}}, S_{\mathrm{Fc}}\right)-\mathbf{2 0 f}$ 催化体系催化查尔酮与亚氨基酯的 环加成反应时, 显示了良好的 endo/exo 选择性(endo/exo $=91 / 9 \sim 96 / 4)$ 和较高的对映选择性 (ee>98\%). 这一成果 在二茂铁衍生物作为配体的金属催化的五元杂环化合物 
的合成中具有重要意义.

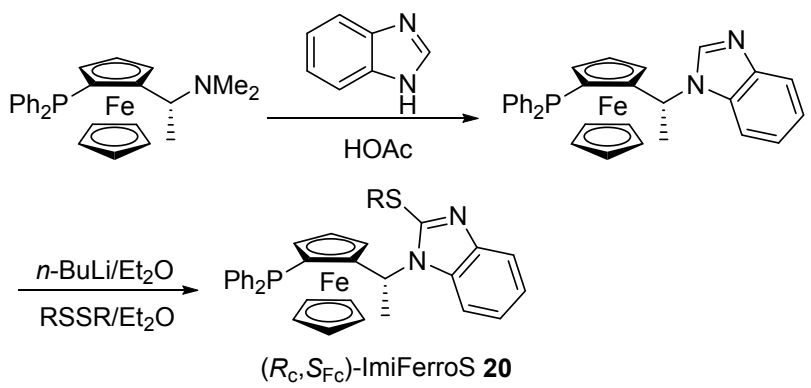

20a: $\mathrm{R}=\mathrm{Ph}$

20b: $\mathrm{R}=p-\mathrm{CH}_{3} \mathrm{C}_{6} \mathrm{H}_{4}$

20c: $\mathrm{R}=p-\mathrm{ClC}_{6} \mathrm{H}_{4}$

20d: $R=B n$

20e: $R=M e$

20f: $\mathrm{R}=i-\mathrm{Pr}$
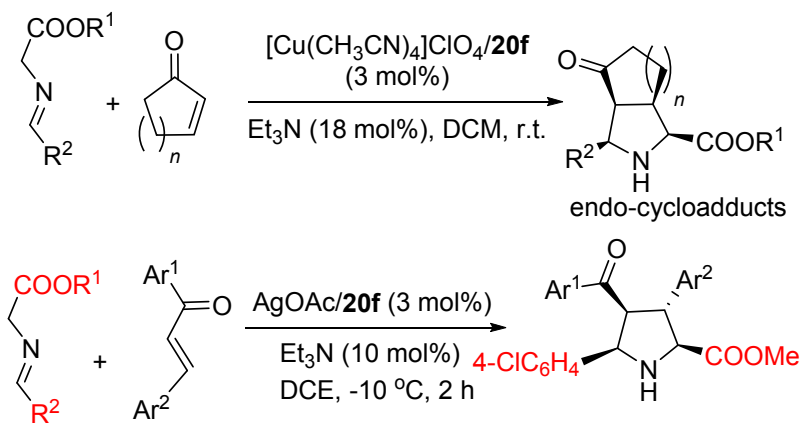

图式 8 新型手性二茂铁基 $P, S$-配体的合成及其催化不对称 $[3+2]$ 环加成反应

Scheme 8 Synthesis of new chiral ferrocenyl $P, S$-ligands and catalytic asymmetric $[3+2]$ cycloaddition reactions

2015 年, Scheidt 等 ${ }^{[28]}$ 设计合成了一种二茂铁基 $N$ 杂环卡宾(NHC)手性咔唑并吡啶盐催化剂(+)-21, 并将 其应用于催化苯甲酰甲酸酯和肉桂醛的环加成反应中 (Eq. 10). 结果发现, 与同类非二茂铁基催化剂相比, 该 二茂铁基 $N$-杂环卡宾手性咔唑并吡啶盐催化剂具有良 好的催化活性和对映选择性, 主要是由于 $\mathrm{NHC}$ 中引

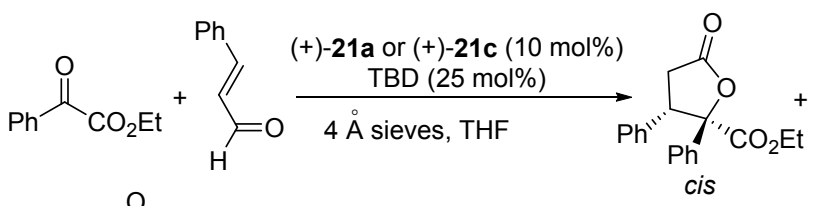

$$
\begin{gathered}
\text { trans } \\
\mathrm{TBD}=1,5,7 \text {-triazabicyclo[4.4.0]dec-5-ene }
\end{gathered}
$$

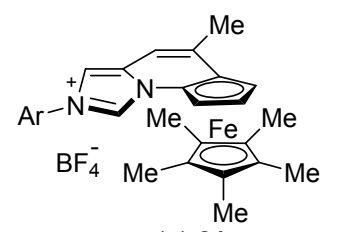

(+)-21a: $\mathrm{Ar}=2,4,6-\mathrm{Me}_{3} \mathrm{C}_{6} \mathrm{H}_{2}$

(+)-21b: $\mathrm{Ar}=\mathrm{Ph}$

(+)-21c: $\mathrm{Ar}=2,4-\mathrm{MeO}_{2} \mathrm{C}_{6} \mathrm{H}_{3}$

(+)-21d: $\mathrm{Ar}=3,5-\left(\mathrm{CF}_{3}\right)_{2} \mathrm{C}_{6} \mathrm{H}_{3}$
入二茂铁基团后有效增加了 $\mathrm{NHC}$ 的电子效应. 同时该 二茂铁基 $\mathrm{NHC}$ 催化剂与 $\mathrm{CuCl}$ 进行配位可得到一种二茂 铁基 NHC-铜配合物，其对烯烃的不对称还原嗍基化偶 联反应具有良好的催化活性和对映选择性，进一步说明 该二茂铁基 $N$-杂环卡宾 $(\mathrm{NHC})$ 手性咔唑并吡啶盐不仅 可以作为 Lewis 碱催化剂使用, 而且是一种良好的过渡 金属配合物催化剂的配体.

\section{2 不对称[3+3]环加成反应}

2012 年, $\mathrm{Hu}$ 等 ${ }^{[29]}$ 报道了一种三齿二茂铁基 $P, N, N$ 配体 22 与 $\mathrm{Cu}(\mathrm{OAc})_{2} \cdot \mathrm{H}_{2} \mathrm{O}$ 共催化的炔丙基酯与环状烯胺 的不对称 $[3+3]$ 环加成反应(Eq. 11), 该催化体系在温和 条件下可以非常高的非对映选择性选择性(endo/exo > 98/2)和对映选择性(up to $98 \%$ ee)得到 endo-加成产物, 该反应底物适用范围广, 不仅具有较高的收率及较好的 非对映选择性和对映选择性，通过该反应合成的产物在 进一步衍生化的过程中其构型可以得到有效保持. 该反 应发展了一种条件温和、底物适用范围广、高立体选择 性和高对映选择性的合成具有重要光学活性价值的双 环[n.3.1]骨架化合物的方法.

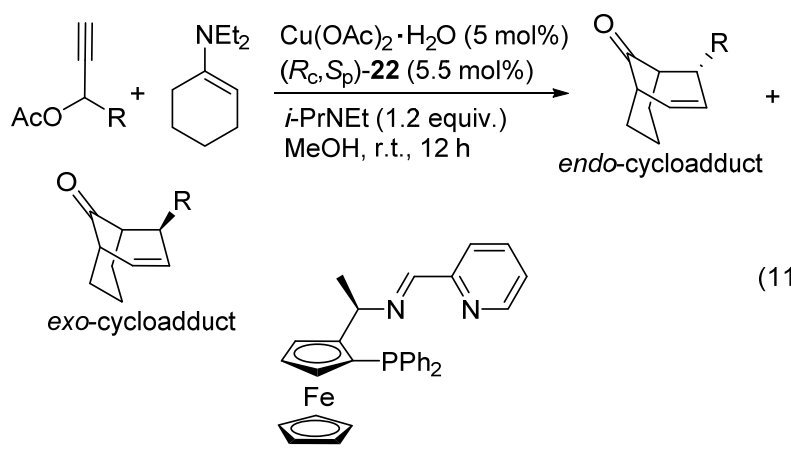

$\left(R_{\mathrm{C}}, S_{\mathrm{p}}\right)-22$

\section{$4.3[2+2+2]$ 环加成反应}

环加成反应可以一步同时构建多个化学键, 是目前 国内外研究最为活跃的领域之一. 相比于传统方法, 过 渡金属催化的 $[2+2+2]$ 环加成反应是合成多取代苯或 吡啶衍生物的有效手段. 2015 年, Fürstner 等 ${ }^{[30]}$ 报道了一 种基于烷基化的二磷铁配合物 23 催化的炔烃或炔烃与 氧基化合物的 $[2+2+2]$ 环加成反应合成六取代苯或六 取代吡啶的研究(Scheme 9). 该反应在二烷基溴化镁和 二炔烃的作用下, $\left[\mathrm{L}_{2} \mathrm{FeX}_{2}\right.$ ] 型铁配合物 $\mathbf{2 3}$ 被还原得到二 烯或二炔配位的 $\left.\left[\mathrm{L}_{2} \mathrm{Fe} \text { (alkene) }\right)_{2}\right]$ 或 $\left[\mathrm{L}_{2} \mathrm{Fe}\right.$ (diene) $]$ 型零价铁 配合物中间体，继而再与一分子炔烃或氰基化合物发生 环加成反应得到目标产物, 产率可高达 $97 \%$. 其最大的 意义在于首次使用铁配合物催化剂来催化炔烃的三聚 反应，通过该反应不仅可以实现六取代苯的高效合成， 
而且可以高效合成五取代吡啶衍生物. 该反应条件相对 较温和，原料容易获得，因此极具应用潜力.

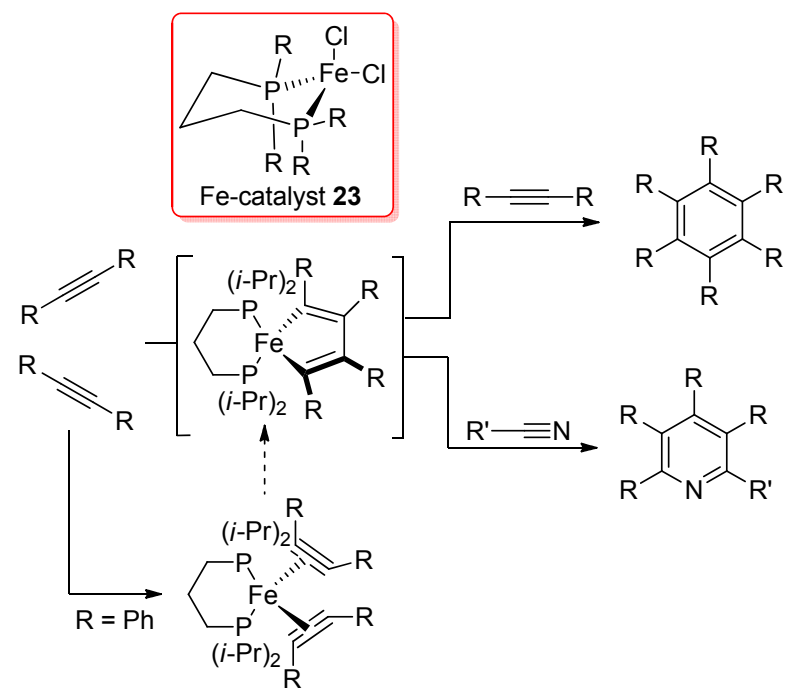

图式 $9\left[\mathrm{~L}_{2} \mathrm{FeX}_{2}\right]$ 型铁配合物及其催化炔烃的 $[2+2+2]$ 环三 聚反应

Scheme 9 Iron complexes of type $\left[\mathrm{L}_{2} \mathrm{FeX}_{2}\right]$ and their catalyzed the $[2+2+2]$ cyclotrimerization of alkynes

\section{5 氧化与还原反应}

\section{1 氧化反应}

\subsection{1 烯烃不对称环氧化反应}

光学活性环氧化合物是非常高效的有机合成中间 体, 其结构中的三元环具有特殊的张力, 可通过选择性 开环和官能团转化等反应合成许多有价值的手性化合 物和天然产物. 环氧化合物也是一类具有良好粘结、耐 腐蚀、高绝缘强度等性能的材料, 已广泛应用于许多工 业领域. 因此, 探索制备环氧化合物特别是具有光学活 性的环氧化合物一直是有机化学研究的重点. 2013 年, Costas 等 ${ }^{[10 b]}$ 设计合成了几种 non-heme 铁配合物催化剂 24, 在催化量的有机羧酸存在下将该配合物应用于烯烃 与双氧水的不对称环氧化反应(Eq. 12). 结果表明, 该配

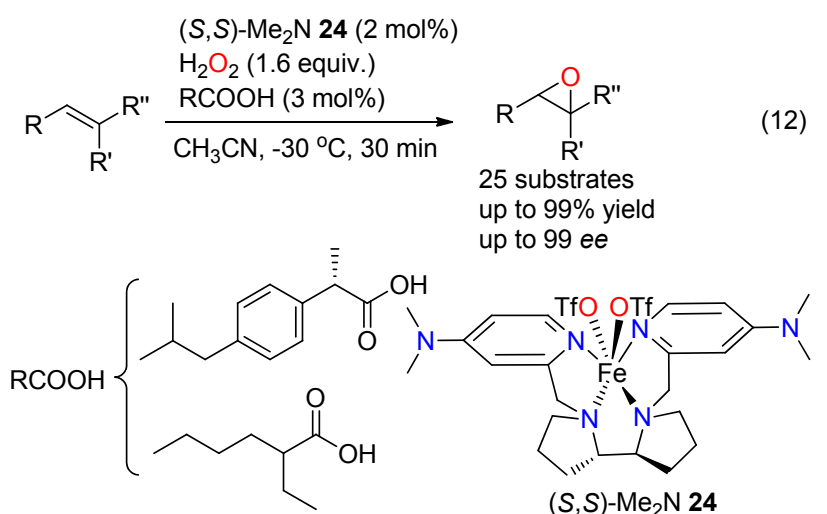

合物催化剂具有较高的对映选择性，且作用于中心铁原 子的配体的电子效应可与有机羧酸协同作用可有效促 进 $\mathrm{O}-\mathrm{O}$ 键断裂, 在较短的时间内即可以较高产率得到 相应的环氧化产物, 该催化剂同时显示了较高的化学选 择性, 不足之处是该催化剂对末端烯烃的环氧化反应没 有催化活性.

2015 年, 该课题组 ${ }^{[31]}$ 将上述配合物配体结构进行 了修饰，合成得到几种新颖的 non-heme 铁配合物催化 剂 $25 \mathbf{a} \sim 25 \mathrm{c}(\mathrm{PDP}-\mathrm{Fe})$ ), 在 $N$-保护的氨基酸衍生物 $N$-Npha-ILeu-OH 作为共配体的作用下, 将该配合物应 用于 $\alpha$-取代苯乙烯的不对称环氧化反应中(Eq. 13). 结 果表明，当以氨基酸作为共配体与 PDP-Fe 型铁配合物 共同作用时，氨基酸可以与中心铁原子协同作用，能够 有效提高双氧水的活性，催化一些难以环氧化的末端烯 烃而得到相应的环氧化产物, 并具有较高的对映选择性 (up to $97 \% e e$ ). 该催化剂显示了良好的催化活性，具有 底物适用范围广、实验条件温和、反应时间短等优点, 发 展了一种高效催化末端烯烃环氧化反应的配合物催化 剂.
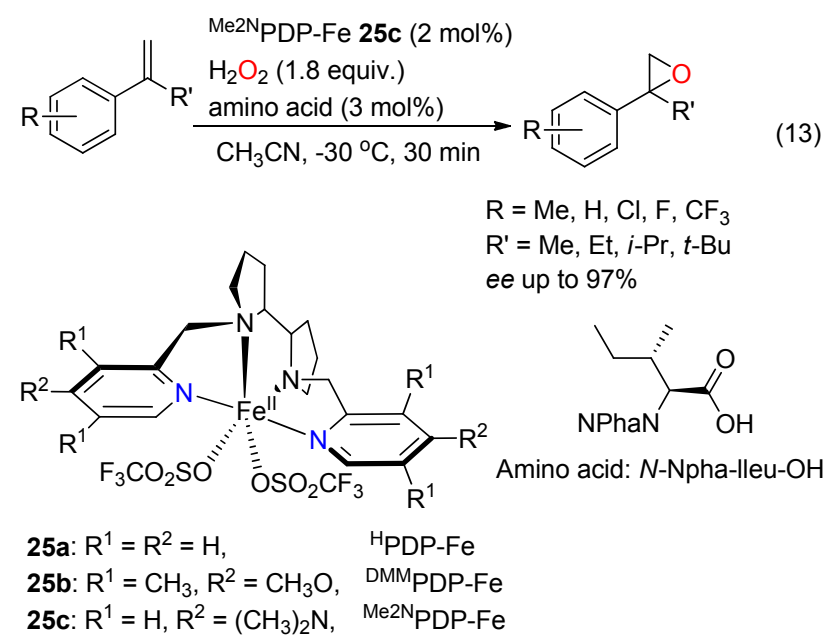

\section{1 .2 芳环的氧化开环反应}

2015 年, Paine 等 ${ }^{[32]}$ 报道了以一种三齿铁配合物为 催化剂, $\mathrm{O}_{2}$ 存在下的邻氨基苯酚(2-Aminophenol, AP)氧 化芳环开环合成吡啶-2-甲酸的研究 (Scheme 10). 所使 用的铁配合物为一种双吡啶一脲基三齿铁(II)配合物 26, 该铁配合物首先与邻氨基苯酚发生配位反应分离得到 一种 2-氨基苯酚盐的铁(III) 配合物 $\left[\left(t-\mathrm{Bu}-\mathrm{L}^{\mathrm{Me}}\right) \mathrm{Fe}^{\mathrm{III}}\right.$ $(4,6-\mathrm{di}-t-\mathrm{Bu}-\mathrm{AP})]\left(\mathrm{ClO}_{4}\right)$, 该铁(III)配合物继而与 $\mathrm{O}_{2}$ 反应 可使得 4,6-二叔丁基-2-氨基苯酚中羟基邻位的 $\mathrm{C}-\mathrm{C}$ 键 区域选择性断裂，然后再发生羰基与氨基的缩合反应得 到最终产物吡啶-2-甲酸衍生物. 研究结果表明, 所使用 的铁配合物中嫝基基团是必须的，如果配体中不含脲基 团, 则配合物不具有使芳环 $\mathrm{C}-\mathrm{C}$ 键断裂开环的催化活 
性，这将对邻氨基苯酚类化合物的氧化芳环开环反应配 合物催化剂中配体结构的设计合成提供一种新的思路.

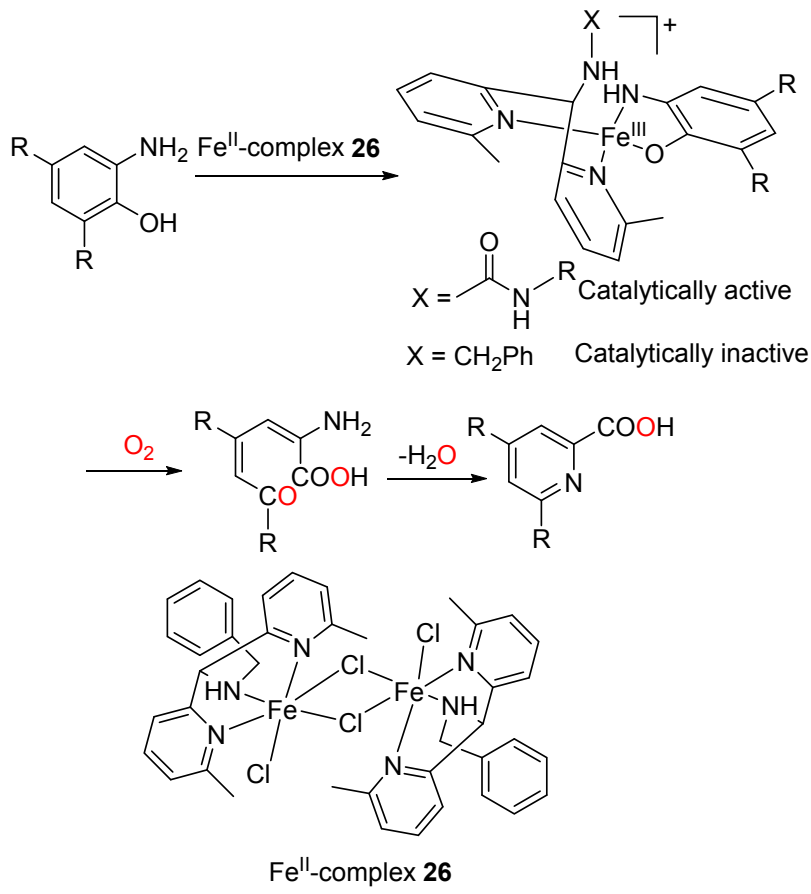

图式 10 非血红素铁配合物催化的 2-氨基苯酚与氧的芳环氧 化开环反应

Scheme 10 Oxygenative aromatic ring cleavage of 2-aminophenol with dioxygen catalyzed by a nonheme iron complex

\section{2 不对称还原反应}

\subsection{1 苯乙酮的不对称还原反应}

具有光学活性的 $\alpha$-苯乙醇作为一种基本的手性中 间体，在手性化合物的合成中具有重要地位， $\alpha$-苯乙醇 在医药、农药、香料等化工行业有着极其广泛的应用 ${ }^{[33]}$. 在不对称合成的研究中, 手性 $\alpha$-苯乙醇的合成有着极为 重要的作用, 它可以被用来从一些非常简单的起始原料 制备一些重要的手性中间体，也能够在一些复杂天然产 物的不对称合成中用来创造最初的手性中心.

苯乙酮的不对称还原得到具有光学活性的 $\alpha$-苯乙 醇的研究较早, 也较为系统, Morris 课题组在该领域坚 持不解地工作, 并合成得到多种与 $P, N$ 原子配位的三 齿、四齿铁配合物, 以异丙醇作为氢源, 实现了苯乙酮 的不对称氢化还原反应，以优异的对映选择性实现手性 $\alpha$-苯乙醇的不对称合成. 近年来该课题组 ${ }^{[34]}$ 在六元和五 元四齿 $P, N, N, P$-型铁配合物的设计合成及其催化苯乙酮 的不对称氢化反应领域开展了系统研究工作, 取得了系 列重要研究成果.

2011 年, 该课题组 ${ }^{[35]}$ 报道了一种五元芳基取代的 铁(II)羊炭基 $P, N, N, P$-型配合物 $\mathbf{2 6}$ 及其对苯乙酮的不对称 催化氢化反应(asymmetric transfer hydrogenation, ATH)
研究(Eq. 14). 首先合成了系列五元 $(S, S)$-trans-[Fe(CO)$\left.(\mathrm{Br})\left(\mathrm{PR}_{2}-\mathrm{CH}_{2} \mathrm{CHdNCH}(\mathrm{Ph}) \mathrm{CH}(\mathrm{Ph}) \mathrm{NdCHCH} \mathrm{CH}_{2}\right)\right] \mathrm{X}$ 配 合物 $\left(27 \mathbf{a} \sim 27 \mathbf{c}, \mathrm{X}=\mathrm{BPh}_{4} ; \mathbf{2 7 d}, \mathbf{2 7 e}, \mathrm{X}=\mathrm{BF}_{4}\right)$, 其中三种 含有甲基取代的芳基基团 $\left[\mathbf{a}\right.$ : $\mathrm{R}=$ para $-\mathrm{CH}_{3} \mathrm{C}_{6} \mathrm{H}_{4} ; \mathbf{b}$ : $\mathrm{R}=$ ortho- $\left.\mathrm{CH}_{3} \mathrm{C}_{6} \mathrm{H}_{4} ; \mathbf{c}: \mathrm{R}=3,5-\left(\mathrm{CH}_{3}\right)_{2} \mathrm{C}_{6} \mathrm{H}_{3}\right]$, 另外两种含有 三氟甲基取代的芳基基团 $\left(\mathbf{d}: \mathrm{R}=\right.$ para $-\mathrm{CF}_{3} \mathrm{C}_{6} \mathrm{H}_{4} ; \mathbf{e}: \mathrm{R}=$ 3,5- $\left.\left(\mathrm{CF}_{3}\right)_{2} \mathrm{C}_{6} \mathrm{H}_{3}\right)$. 以异丙醇为氢源时, 随后将这五种铁 的配合物应用于催化苯乙酮的不对称氢化反应(ATH)研 究，结果表明，配合物 $27 \mathrm{~b}, 27 \mathrm{~d}, 27 \mathrm{e}$ 的对该反应几乎没 有催化活性，而配合物 27a 却显示了非常高的催化活性， 催化活性在 $28{ }^{\circ} \mathrm{C}$ 时高达 $30000 \mathrm{~h}^{-1}$, 是已见报道的催化 ATH 反应的铁配合物催化剂中催化活性最高的催化剂. 配合物 27c 催化 ATH 反应时，显示了较高的对映选择 性, ee 值高达 $90 \%$, 是已见报道的选择性最高的铁配合 物催化剂.

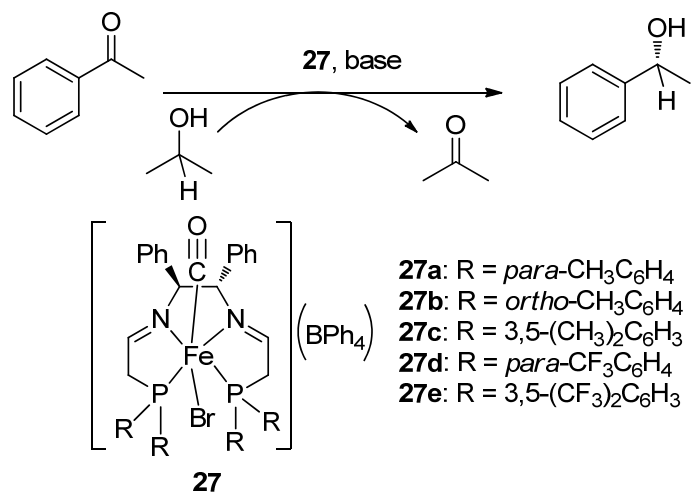

随后, 该课题组 ${ }^{[36]}$ 利用动力学及其研究方法又对 上述铁配合物催化苯乙酮的氢化还原反应的催化机理 进行了深入研究(Scheme 11), 并撰文详细报道.

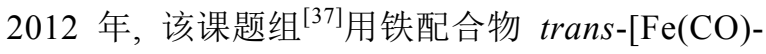
$\left.(\mathrm{MeCN})\left(\mathrm{PPh}_{2} \mathrm{C}_{6} \mathrm{H}_{4} \mathrm{CH}=\mathrm{NCH}_{2}\right)_{2}-\kappa^{4} P, N, N, P\right]\left(\mathrm{BF}_{4}\right)_{2}$ (28) 在苯溶剂中与异丙醇钾作用得到一种结构不同寻常的 铁配合物 trans- $\left[\mathrm{Fe}(\mathrm{CO})\left(\mathrm{PPh}_{2} \mathrm{C}_{6} \mathrm{H}_{4} \mathrm{CH}=\mathrm{NCH}_{2} \mathrm{CH}_{2} \mathrm{NH}-\right.\right.$ $\left.\left.\mathrm{CHC}_{6} \mathrm{H}_{4} \mathrm{PPh}_{2}\right)-\kappa^{5} P, N, C, N, P\right]\left[\mathrm{BF}_{4}\right](\mathbf{2 9})$. 并将其应用于催 化苯乙酮的氢化还原反应中(Scheme 12), 进一步的研 究发现，使用配合物 28 作为苯乙酮的氢化还原反应的 催化剂时，在完成苯乙酮的氢化还原反应的同时配合物 28 也可以转化为配合物 $\mathbf{2 9}$, 经密度泛函理论(DFT)计算 及机理研究发现, 反应体系中加入的异丙醇可作为苯乙 酮氢化还原反应的氢源, 首先异丙醇配位到中心铁原子 上得到配合物 $30_{\mathrm{DFT}}$, 继而发生氢转移还原亚胺反应得 到含活性氢的配合物 31 DFT, 最后配合物 31 DFT 完成苯乙 酮的氢化还原反应而得到铁配合物 29. 这一研究可以 实现 $P, N, N, P$-型铁配合物不同结构之间的相互转化, 同 时实现苯乙酮的催化氢化还原，这种 “一箭双雕” 的方 


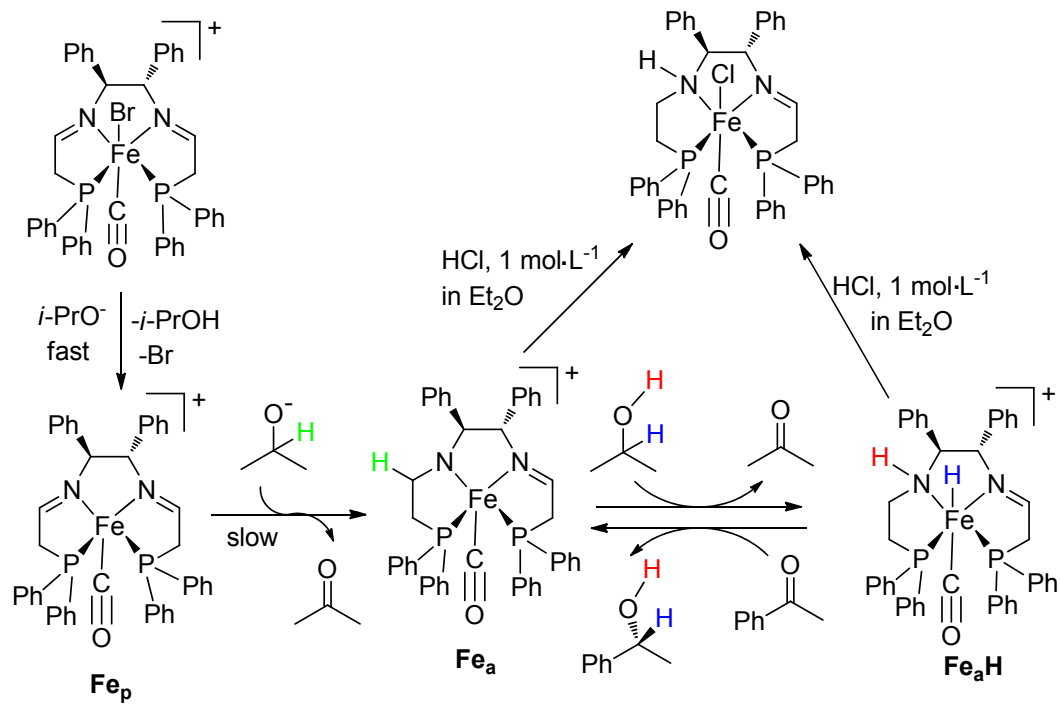

图式 11 铁配合物催化苯乙酮的不对称氢转移反应及其机理

Scheme 11 Mechanism of asymmetric transfer hydrogenation of acetophenone using an iron(II) complexes

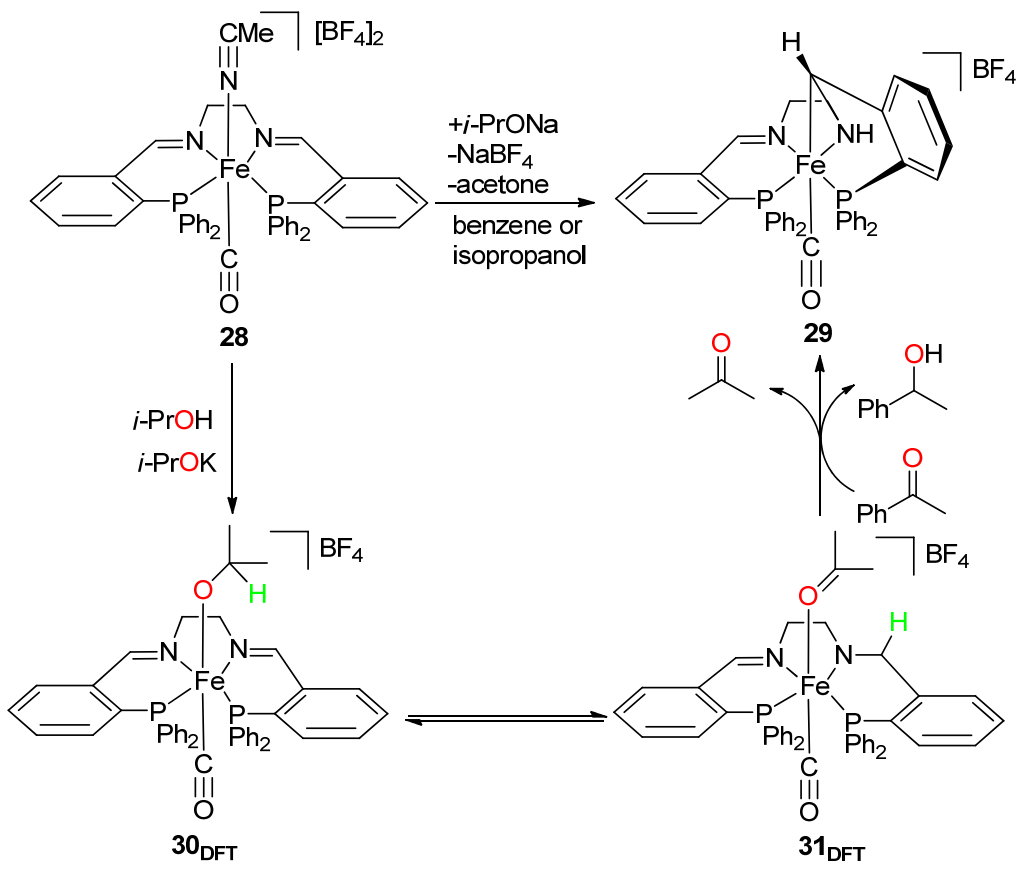

图式 12 反式铁配合物的相互转化及催化苯乙酮的不对称氢转移反应

Scheme 12 Asymmetric transfer hydrogenation of acetophenone using the trans-iron(II) complexes

法同时解决了配合物合成及其催化活性应用的问题.

2013 年, 该课题组 ${ }^{[38]}$ 从一种季磷盐出发, 经多步反 应合成得到一种部分饱和的胺/亚胺二磷配位的 $P, N H, N, P$-型铁(II)配合物 33a 33c. 在异丙醇作氢源的 条件下, 将其用于还原酮或亚胺得到具有光学活性的醇 或胺的衍生物(Scheme 13). 结果表明, 该类催化剂在温 和条件下, 有很高的催化活性, $28{ }^{\circ} \mathrm{C}$ 时其催化转化效率 可高达 $200 \mathrm{~s}^{-1}$, 同时对该催化反应提出了一种催化循 环机理, 并通过光谱学手段检测到了其中的铁的氢化物 及酰胺的中间体.
2012 年, 该课题组 ${ }^{[39]}$ 发展了一种内球活化-外球催 化的 $P, N, N, P$ - 型铁配合物催化剂 $\mathbf{3 4}$, 并利用 DFT 量子化 学计算方法研究了其催化苯乙酮还原为 $\alpha$-苯乙醇的催 化机理(Scheme 14), 研究发现, 在最初的活化阶段需要 1 equiv. 的异丙醇还原双胺配合物，继而逐步完成酮的 氢化还原反应. 该配合物催化剂被认为在酩的加氢反应 中具有较好的催化活性, 同时在后续的氢负离子转移阶 段具有良好的阻隔能力和较高的活化能, 有望为其他更 有效的铁催化剂的设计合成提供研究思路和理论依据. 


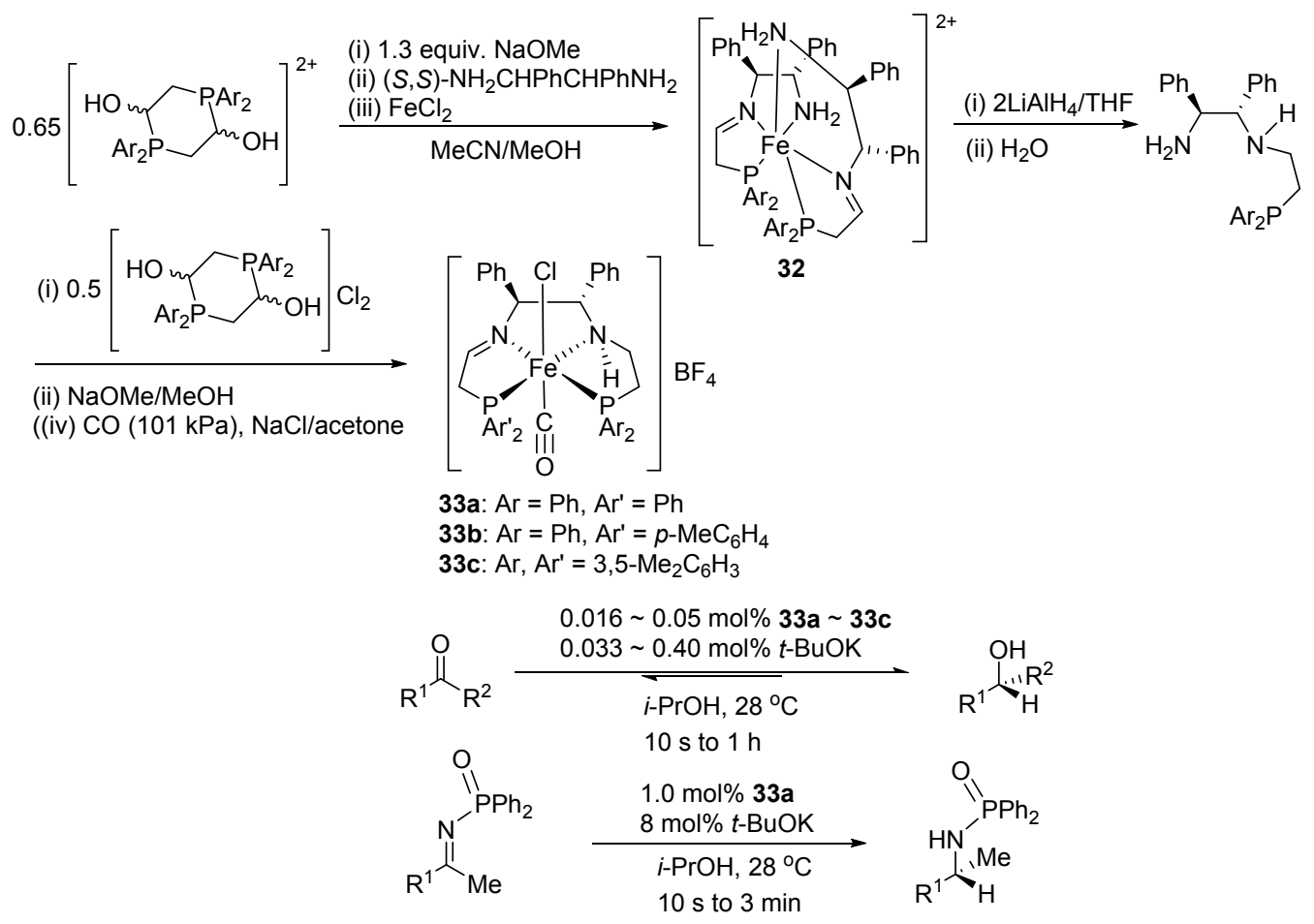

图式 13 胺-亚胺双膦铁配合物的设计合成及其在酮和亚胺的不对称氢化反应中的应用

Scheme 13 Synthesis of amine(imine)diphosphine iron complexes and their application of the asymmetric transfer hydrogenation of ketones and imines

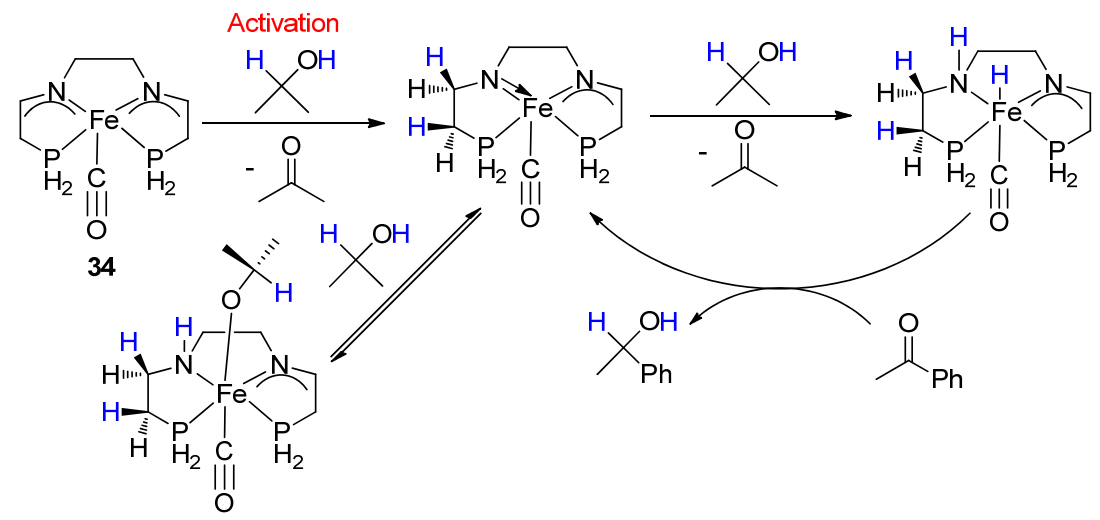

图式 14 PNNP 型铁配合物催化酮的氢转移反应机理

Scheme 14 Mechanism of transfer hydrogenation of ketones using iron(II) PNNP eneamido complexes

2014 年, Morris 课题组 ${ }^{[40]}$ 设计合成了一种新型 $P, N, N, P$ - 型铁配合物 $(S, S)$-trans-[FeCl(CO) $\left(\mathrm{PAr}_{2}-\mathrm{NH}-\right.$ $\left.\mathrm{N}-\mathrm{PAr}_{2}{ }_{2}\right) \mathrm{BF}_{4}$ (35a: $\mathrm{Ar}, \mathrm{Ar}^{\prime}=\mathrm{Ph} ; 35 \mathbf{b}: \mathrm{Ar}=\mathrm{Ph}, \mathrm{Ar}^{\prime}=$ 4- $\mathrm{MeC}_{6} \mathrm{H}_{4} ; 35 \mathrm{c}$ : $\left.\mathrm{Ar}, \mathrm{Ar}^{\prime}=3,5-\mathrm{Me}_{2} \mathrm{C}_{6} \mathrm{H}_{3}\right)$, 并应用于催化 苯乙酮的不对称加氢还原反应(Scheme 15). 研究结果 表明, 在 $t$-BuOK/2-propanol 体系中, 该催化剂对酮的不 对称加氢还原反应具有良好的催化活性, 当配体中含有 较大的双二甲苯基膦基基团时, 催化活性明显降低, 但 有良好的对映选择性. 同时结合 DFT 量子化学理论计 算, 研究了该类配合物催化剂的催化循环机理.
2014 年, Morris 课题组 ${ }^{[41]}$ 合成了一类 $P, N, P^{\prime}$-型和 $P, N H, P^{\prime}$-型钳形手性铁配合物 mer, trans-[Fe(P-N-P')$(\mathrm{CO})_{2} \mathrm{Br}_{\mathrm{B}} \mathrm{BF}_{4}(37)$, 并将其应用于酮的加氢还原反应 $(\mathrm{Eq}$. 15). 首先合成了 $\mathrm{R}$ 取代基分别为苯基、苯甲基和异丙基 的三种 $\left[\mathrm{Fe}\left(\mathrm{PCy}_{2} \mathrm{CH}_{2} \mathrm{CH}=\mathrm{NCH}(\mathrm{R}) \mathrm{CH}_{2} \mathrm{PPh}_{2}\right)(\mathrm{CO})_{2} \mathrm{Br}\right] \mathrm{BF}_{4}$ 配合物, 并用于苯乙酮加氢还原反应中，显示了较好的 催化效果. 在对配体结构进行修饰时发现，当 $\mathrm{R}$ 基团换 为含氮的基团时，所获得的铁配合物的催化活性大为降 低. 为进一步拓展配体结构, 该课题组又合成了系列六 元 $P, N, P^{\prime}$-型和 $P, N H, P^{\prime}$-型铁配合物催化剂 $\left[\mathrm{Fe}\left(\mathrm{P}-\mathrm{N}-\mathrm{P}^{\prime}\right)-\right.$ 


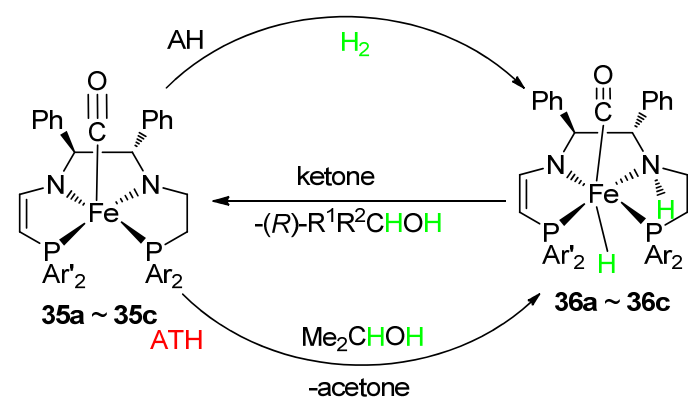

图式 15 含胺-亚胺双膦配体的 P-NH-N-P 型铁配合物催化酮 的不对称氢化和不对称转移氢化反应

Scheme 15 Iron catalysts containing amine(imine)diphosphine P-NH-N-P ligands catalyze both the asymmetric hydrogenation (AH) and asymmetric transfer hydrogenation (ATH) of ketones

$\left.(\mathrm{NCMe})_{3}\right]\left[\mathrm{BF}_{4}\right]_{2}$ 和 $\left[\mathrm{Fe}\left(\mathrm{P}-\mathrm{NH}-\mathrm{P}^{\prime}\right)(\mathrm{NCMe})_{3}\right]\left[\mathrm{BF}_{4}\right]_{2}$, 但是催 化结果表明这两类催化剂均没有催化活性. 最后该课题 组合成了一种非手性的 mer, cis- $\mathrm{Fe}\left(\mathrm{PPh}_{2}-\left(o-\mathrm{C}_{6} \mathrm{H}_{4}\right)-\right.$ $\left.\mathrm{CHNCH}_{2} \mathrm{CH}_{2} \mathrm{PPh}_{2}\right)(\mathrm{CO}) \mathrm{Br}_{2}$ 催化剂, 催化苯乙酮的直接 加氢还原反应. 结果表明, 该类催化剂具有良好的催化 活性和对映选择性(TOF up to $1980 \mathrm{~h}^{-1}$, ee up to $80 \%$ ).
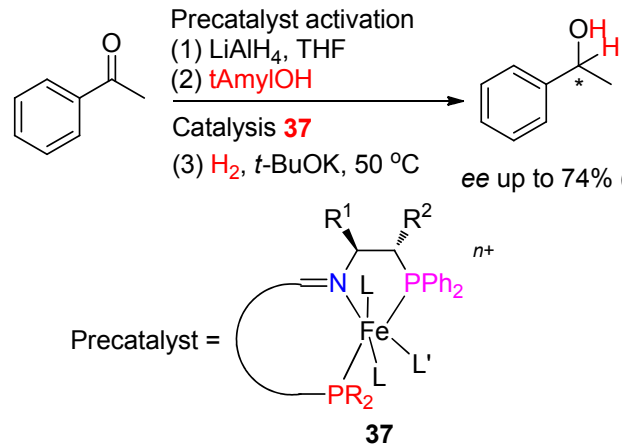

同年, 该课题组 ${ }^{[22]}$ 以配合物 38 为底物, 经 $\mathrm{LiAlH}_{4}$ 和醇处理后得到一种新颖的 $P, N, P^{\prime}$-型羰基含氢铁配合 物催化剂 39 (mer-trans-[Fe $\left.(\mathrm{Br})-(\mathrm{CO})_{2}\left(\mathrm{P}-\mathrm{CH}=\mathrm{N}-\mathrm{P}^{\prime}\right)\right]-$ $\left.\left[\mathrm{BF}_{4}\right]\right)\left(\mathrm{P}-\mathrm{CH}=\mathrm{N}-\mathrm{P}^{\prime}=\mathrm{R}_{2} \mathrm{PCH}_{2} \mathrm{CH}=\mathrm{NCH}_{2} \mathrm{CH}_{2} \mathrm{PPh}_{2}, \mathrm{R}=\right.$ $\mathrm{Cy}, i-\mathrm{Pr}$ 和 $\mathrm{P}-\mathrm{CH}=\mathrm{N}-\mathrm{P}^{\prime}=(S, S)-\mathrm{Cy}_{2} \mathrm{PCH}_{2} \mathrm{CH}=\mathrm{NCH}(\mathrm{Me})-$ $\mathrm{CH}(\mathrm{Ph}) \mathrm{PPh}_{2}$ ). 并将该系列配合物催化剂应用于催化酮 和亚胺的不对称加氢还原反应(Scheme 16), 结果表明, 当催化剂配体中 $\mathrm{R}=\mathrm{Ph}$ 基团时, 配合物无催化活性. 其 余手性铁配合物催化剂催化酮的不对称氢化还原反应 中可以高达 $85 \%$ 的 $e e$ 值得到系列(S)-醇, 催化剂的 TOF 达到 $2000 \mathrm{~h}^{-1}$, TON 达到 5000. 对亚胺的不对称催化氢 化时 $e e$ 值可达到 $90 \%$, 但 TOF 和 TON 则分别只有 $20 \mathrm{~h}$ ${ }^{-1}$ 和 99. 同时该课题组利用 NMR 和 DFT 等手段对该配 合物不对称催化的催化机理进行了研究.

2015 年, 该课题组 ${ }^{[43]}$ 又报道了一种从简单易得原 料 $\mathrm{Ph}_{2} \mathrm{PH}$ 出发经多步反应合成得到铁配合物四氟硼酸

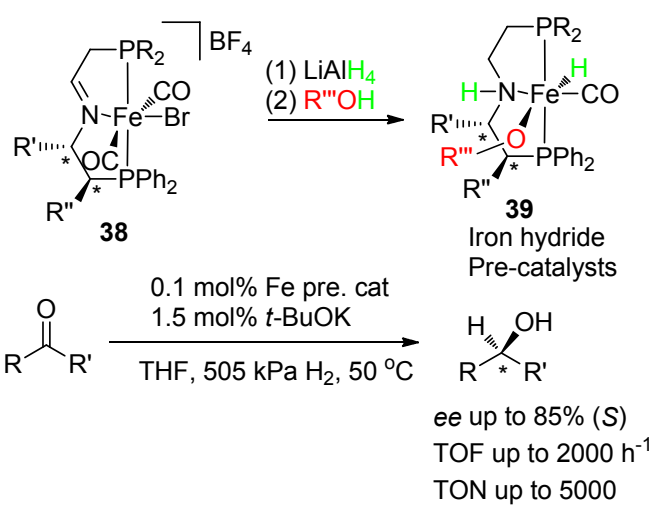

图式 16 非对称 PNP'钳形铁配合物催化剂及其催化酮的不对 称氢化反应

Scheme 16 Iron(II) complexes containing unsymmetrical PNP' pincer ligands and the catalytic asymmetric hydrogenation of ketones

化反式胺-亚胺二膦基一氯羰基铁(II)配合物(40)的研究, 以异丙醇作为氢源将其应用与芳乙酮和亚胺的不对称 氢化还原反应(Scheme 17), 并与传统的钉配合物催化 剂的催化性能进行了比较. 结果表明, 该类铁配合物催 化剂催化还原芳乙酮的反应时催化效果较好，以良好至 优秀产率和 $e e$ 值得到系列手性 $(R)$-醇的衍生物. 在催化 含有二苯基膦酰基 $\left[\mathrm{P}(\mathrm{O}) \mathrm{Ph}_{2}\right]$ 基团的亚胺时，该类配合 物催化具有很高的催化性能和对映选择性, 以更高 的产率和 $e e$ 值得到系列手性仲胺衍生物. 与传统的 钓配合物催化剂相比，虽然钉配合物催化能够得到 更高的 $e e$ 值, 但钓配合物催化往往需要更长的反应 时间和较大的催化剂用量.

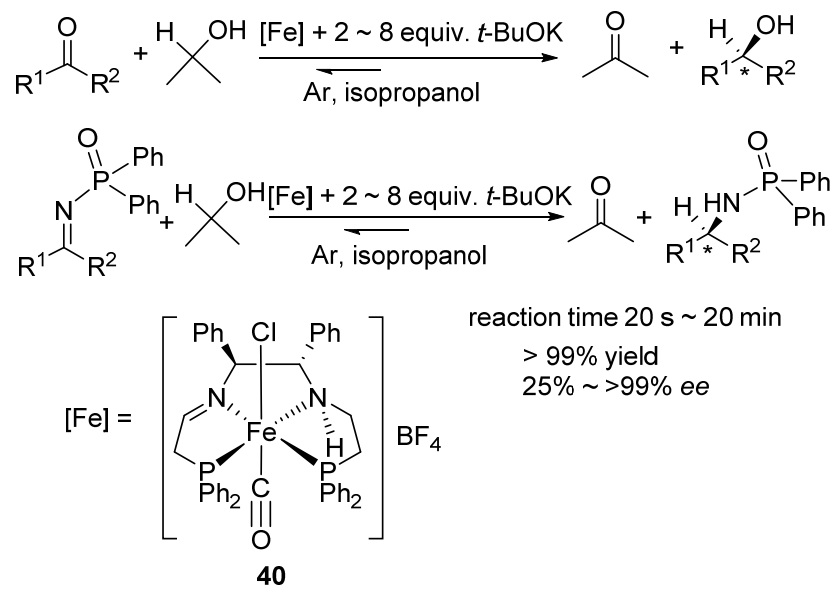

图式 17 胺一亚胺双膦铁配合物催化酮和亚胺的不对称转移 氢化反应

Scheme 17 Amine(imine)diphosphine iron catalyzed the asymmetric transfer hydrogenation of ketones and imines

近期，该课题组 ${ }^{[44]}$ 又利用上述方法合成得到上述 
配合物的一种衍生物 41, 以异丙醇作为氢源的条件下 将其应用于催化芳乙酮的不对称还原反应，仅需 0.02 $0.2 \mathrm{~mol} \%$ 的催化剂用量, 便可以 $40 \% \sim 99 \%$ 的转化率和 高达 $99 \%$ 的 $e e$ 值得到系列手性 $\alpha$-苯乙醇衍生物(Eq. 16).<smiles>[R]C(=O)c1ccccc1</smiles>

$41(0.02 \sim 0.2 \mathrm{~mol} \%)$
$\underset{t-B u O K}{ } \underset{i-\mathrm{PrOH}, 2}{ } 28^{\circ} \mathrm{C}$

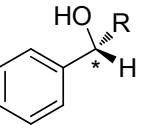

$40 \% \sim 99 \%$ conversion

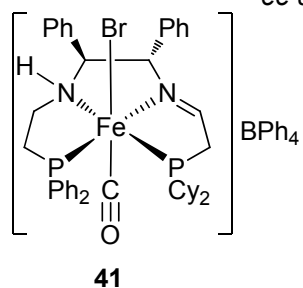

41

在 Morris 课题组研究工作的带动和鼓舞下, 近年来 不断有高效手性铁配合物催化剂应用于苯乙酮的不对 称氢化反应的研究报道出现. 2014 年, Mezzetti 等 ${ }^{[45]}$ 报 道了一种含对称 $\mathrm{N}_{2} \mathrm{P}_{2}$ 大环配体的双异腈铁(II)配合物的 合成, 该配合物可通过简单易得的双异腈类似物合成得 到(Scheme 18). 该类配合物催化剂的合成由相应的大
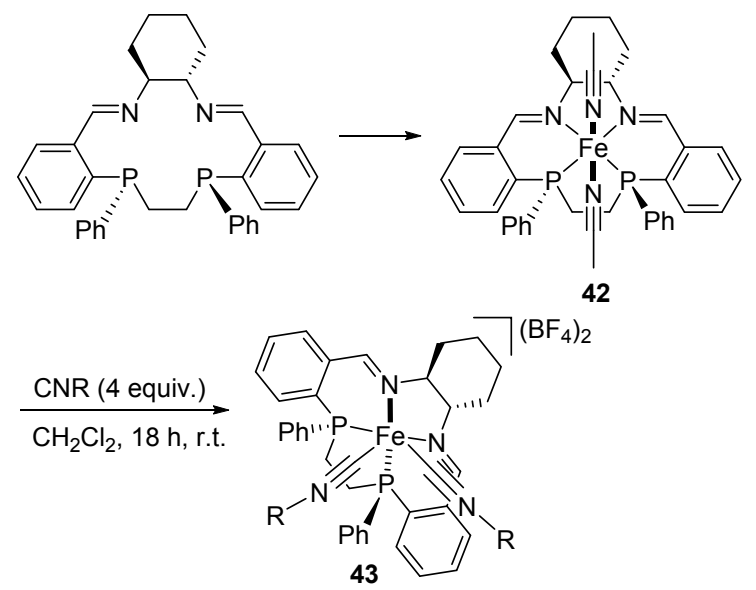

43a: $\mathrm{R}=t-\mathrm{Bu}, 95 \%$

43b: $\mathrm{R}=1-\mathrm{Ad}, 80 \%$

43c: $\mathrm{CMe}_{2}{ }^{\text {neo Pent, }} 79 \%$

43d: $R=$ Cy, $89 \%$

43e: $\mathrm{R}=\mathrm{Ph}, 81 \%$

43f: $R=B n, 85 \%$

43g: $\mathrm{R}=\mathrm{CH}_{2} \mathrm{CO}_{2} \mathrm{Me}, 77 \%$

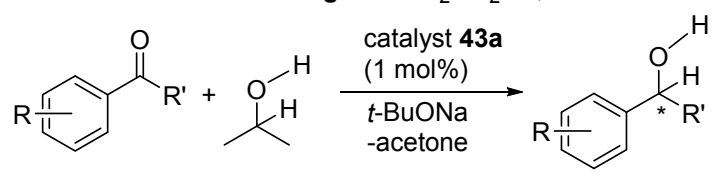

up to $98 \%$ yield up to $91 \%$ ee

图式 18 含手性 $\mathrm{N}_{2} \mathrm{P}_{2}$ 大环配体的双异腈铁配合物的设计合成 及其催化酮的对映选择性转移氢化反应

Scheme 18 Synthesis of diisonitile iron(II) complexes with chiral $\mathrm{N}_{2} \mathrm{P}_{2}$ macrocycles and the catalytic of enantioselective transfer hydrogenation of ketones
环配体底物出发, 先得到相应的乙腈铁(II)配合物 $\left[\mathrm{Fe}(\mathrm{MeCN})_{2}\left(\mathrm{~N}_{2} \mathrm{P}_{2}\right)\right]\left(\mathrm{BF}_{4}\right)_{2}(\mathbf{4 2})$, 继而与 4 equiv. 的取 代异腈反应即可得到双异腈铁(II)配合物催化剂 $\mathbf{4 3}$, 该类配合物催化剂应用于催化酮的氢化还原反应, 结果表明，使用双叔丁基异腈铁(II)配合物催化剂 43a 时, 可以优秀产率得到相应的还原产物, 且具有 良好的对映选择性. 同时相对于已见报道的铁配合 物催化剂来说, 该催化剂对底物的容忍性更好, 即使 催化剂的用量降低至 $1 \mathrm{~mol} \%$ 时，其催化活性仍未见 明显降低.

\subsection{2 其他还原反应}

2012 年, Morris 课题组 ${ }^{[46]}$ 设计合成了几种不对称 $P, N, N, P$-型四齿铁配合物 $\mathbf{4 4}$, 以异丙醇作为氢源条件下, 将该类配合物催化剂应用于催化亚胺的不对称氢化还 原反应，取得了良好的结果(Eq. 17). 温和条件下，以较 低的催化剂用量和 94\% 99\%的 ee 值将亚胺还原为二 级胺类化合物，但是该催化剂对底物的空间位阻较为敏 感，而几乎不受底物电子效应的影响.
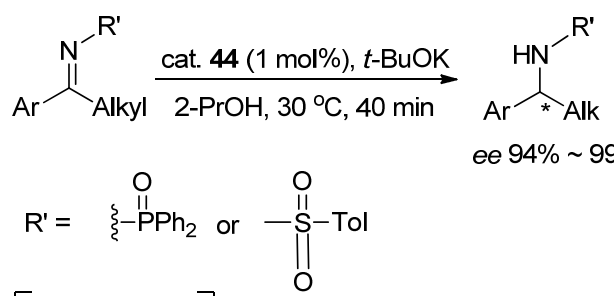

ee $94 \% \sim 99 \%$

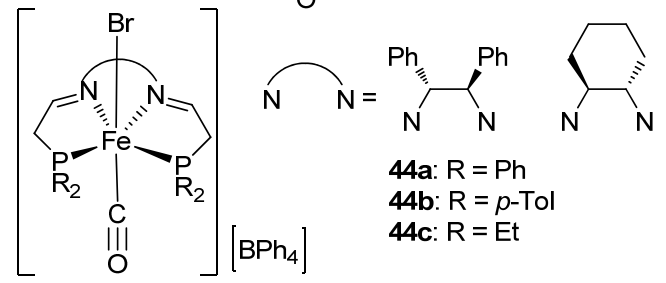

2015 年, $\mathrm{Hu}$ 等 ${ }^{[47]}$ 报道了一种新型 $P O N O P$-型钳形铁 (II)配合物催化的醛的加氢还原反应(Eq. 18). 设计合成 的三种铁配合物催化剂中均含有 2,6-二膦氧基吡啶配体, 且均能在室温下很好的活化 $\mathrm{H}_{2}$ 用于醛的加氢还原反应, 其中配合物 46 和 47 的催化选择性较高. 当芳醛中含有烯 基或酮羰基时，以配合物 46 和 47 作为催化剂时，即可实 现室温下醛基的加氢还原，而保留烯基或酮羰基不受影 响. 研究结果表明, 该类配合物催化剂对底物的普适性 非常好, 无论是芳香醛或是脂肪醛在最优化条件下均能 以较高产率被还原为相应的伯醇衍生物; 对芳醛而言即 使醛基邻位含有强的供电子基(如 $\mathrm{OMe}$ )或强的吸电子基 (如 $\mathrm{NO}_{2}$ ) 也能得到良好以上产率的催化效果. 且当以甲酸 钠作为氢源时, 配合物 46 和 47 也能很好的催化醛的氢化 还原反应得到相应的苯甲醇的衍生物. 


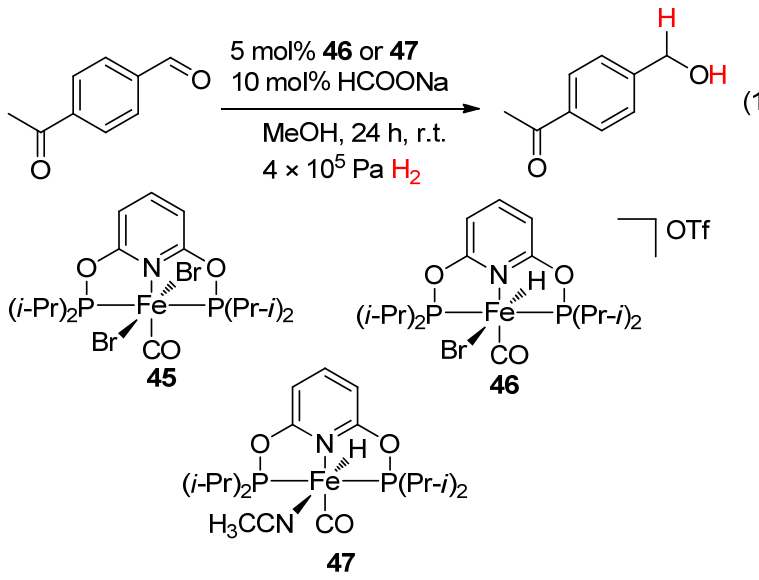

Kuwano 等 ${ }^{[88]}$ 以手性二茂铁双磷(Josiphos ligand)为 配体 48, 分别与碘、 $\mathrm{Yb}(\mathrm{OTf})_{3} 、[\mathrm{IrCl}(\mathrm{cod})]_{2}$ 组成催化体 系 $(\operatorname{cod}=1,5$-cyclooctadiene), 用于催化嘧啶类化合物的 不对称加氢还原反应(Eq. 19). 结果表明, 该催化体系可 将各种 4-取代嘧啶衍生物高产率地还原为 1,4,5,6-四氢 嘧啶化合物, 其中三氟甲磺酸镧系金属对芳环的催化氢 化具有很高的对映选择性(up to $99 \% e e$ ), 且具有较好的 底物适用性.
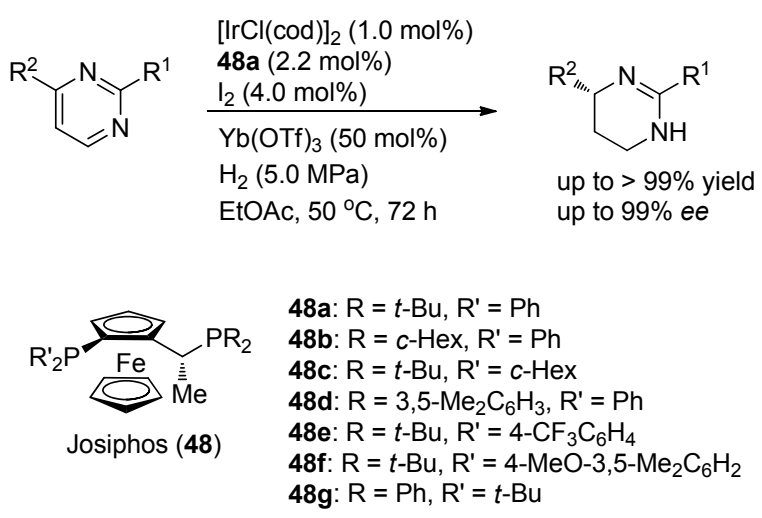

\section{6 其他反应}

\subsection{1,4-加成反应}

有机金属试剂对 $\alpha, \beta$-不饱和羰基化合物的不对称共 轭加成是形成 $\mathrm{C}-\mathrm{C}$ 键的重要反应之一, 其加成产物可 用于制备天然产物和具有生理活性的药物或中间体. 2014 年, Pullarkat 等 ${ }^{[49]}$ 设计合成了一种二茂铁基磷配体, 继而合成得到一种二茂铁基磷环钯配合物 49, 随后将 其应用于环烯酮与芳基苯嗍酸的不对称 1,4-加成反应中 (Eq. 20). 结果表明, 该二茂铁配合物催化剂具有良好的 催化活性和较高对映选择性, 遗憾的是作者并未进一步 拓展底物以研究该催化剂在不对称 1,4-加成反应中的应 用，因此，关于该类配合物在其他不对称有机合成中的 应用及其作用机理尚需投入进行大量研究工作.

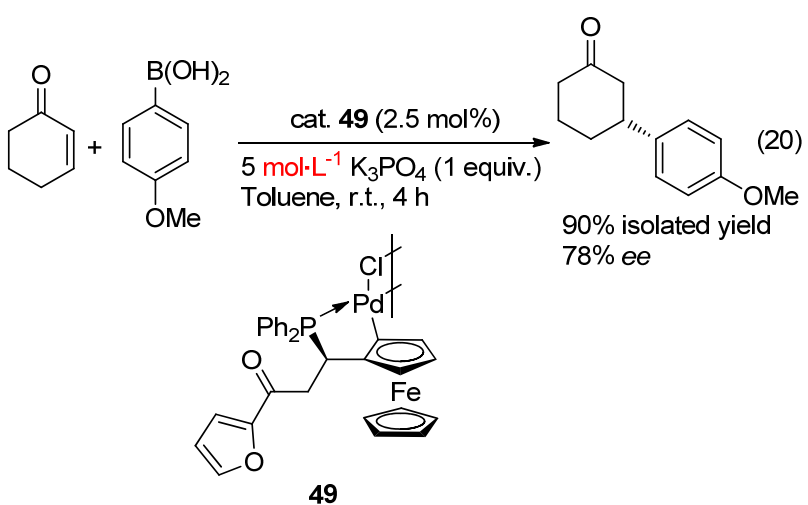

2015 年, Peters 等 ${ }^{[50]}$ 设计合成了几种二茂铁基钯配 合物 50, 并将其应用于催化异噁唑啉酮和甲基乙烯基 酮的不对称 1,4-加成反应(Eq. 21). 研究结果表明, 不对 称加成的对映选择性来自于二茂铁的空间作用. 这是第 一例成功的将二茂铁基钯配合物应用于异噁唑啉酮的 C-直接烷基化反应的例子.

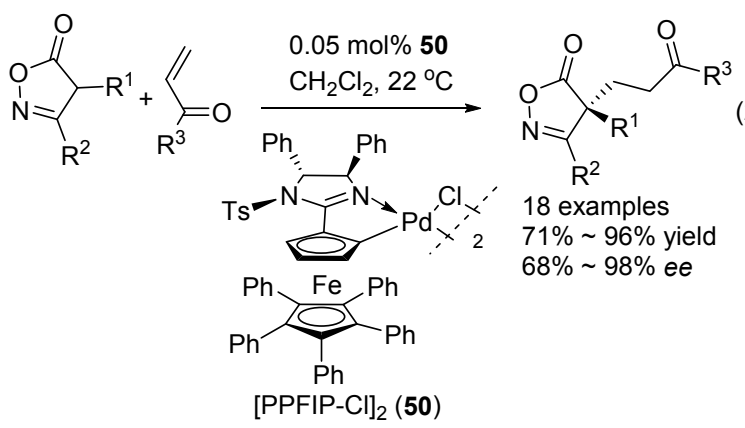

\section{2 芳基卤代烃/芳香烃的氨基化反应}

$\mathrm{C}_{\mathrm{Ar}}-\mathrm{N}$ 键普遍存在于生物活性物及药物中, 芳胺 类化合物广泛用作药物、染料、杀虫剂, 因此含有 $\mathrm{C}_{\mathrm{Ar}}-\mathrm{N}$ 化合物的合成引起了研究者的兴趣. 经典的合 成方法有硝化还原法、Ulmann 合成法以及 $\mathrm{S}_{\mathrm{N}} \mathrm{Ar}$ 合成法. 但是这些方法存在通用性差，合成步骤多，化学选择不 确定，需要苛刻的反应条件等缺点. 在过去几年里，因 为选择性和官能团兼容性的提高, 钯催化卤代芳烃的胺 化已广泛应用于合成芳胺，并且逐渐发展成一个普遍、 可靠和实用的方法. 近年来随着铁配合物催化剂的广泛 应用，研究者将目光指向了铁及其配合物催化合成芳基 胺的研究, 并取得了初步成果.

2014 年, Baran 等 ${ }^{[51]}$ 以二茂铁为催化剂, 在较温和 的实验条件下，实现了芳香环 $\mathrm{C}-\mathrm{H}$ 键的直接氨基化反 应(Scheme 19). 该反应中利用自制的 $N$-琥珀酰亚胺过 酸酯(NSP, $N$-succinimidyl perester)为底物与各种取代的 芳香烃进行反应，可以中等左右的产率得到系列琥珀酰 亚胺基取代的氨基化产物. 机理研究证实, 二茂铁在反 应过程中扮演电子穿梭的角色，通过单电子转移过程促 使过酸酯 $\mathrm{O}-\mathrm{O}$ 键的断裂而形成自由基，继而实现琥珀 
酰亚胺自由基对芳香环的加成反应而得到最终产物. 该 方法除具有实验条件温和、底物适用范围广等优点外, 关键是首次实现了二茂铁催化的单电子转移过程, 为其 他类型有机反应的设计研究提供了一种新思路.

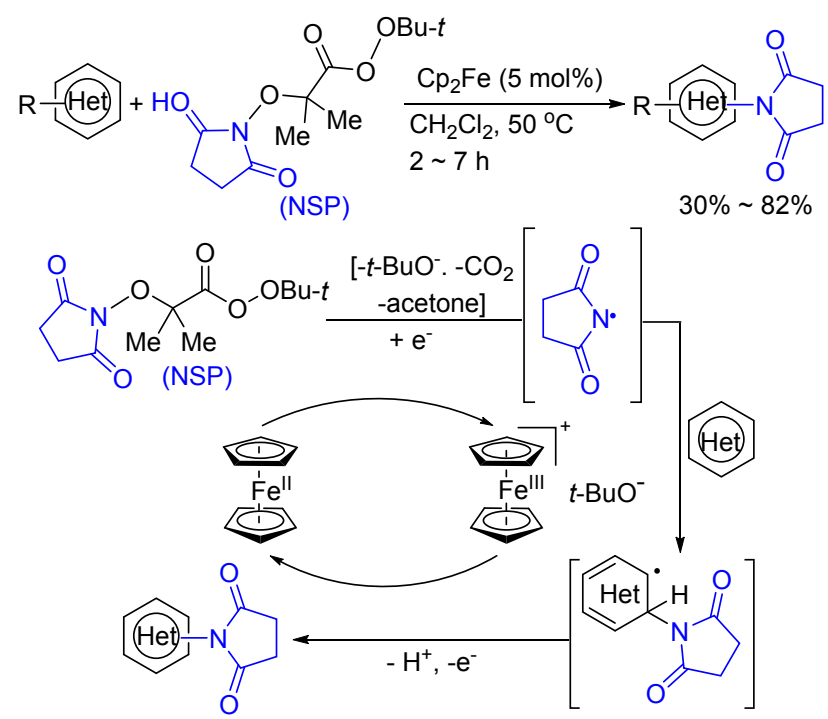

图式 19 二茂铁催化(杂)芳香烃 $\mathrm{C}-\mathrm{H}$ 键的氨基化反应及其可 能的机理

Scheme 9 Ferrocene-catalyzed $\mathrm{C}-\mathrm{H}$ imidation of (hetero)arenes and its proposed mechanism

2015 年, Hartwig 等 ${ }^{[52]}$ 以 Josiphos 配体和 $\eta^{2}$-bound 苯甲腈配体与 $[\mathrm{Ni}(\mathrm{cod})]_{2}$ 进行配位得到一种二茂铁基镍 配合物 51, 该配合物作为催化剂可以很好地催化芳基 亲电试剂(如芳基卤)的氨基化反应(Scheme 20). 研究结 果表明, 在该催化剂作用下, 芳基卤试剂可以与多种胺 化试剂(如氨气、甲基氯化铵、乙基氯化铵等)进行偶

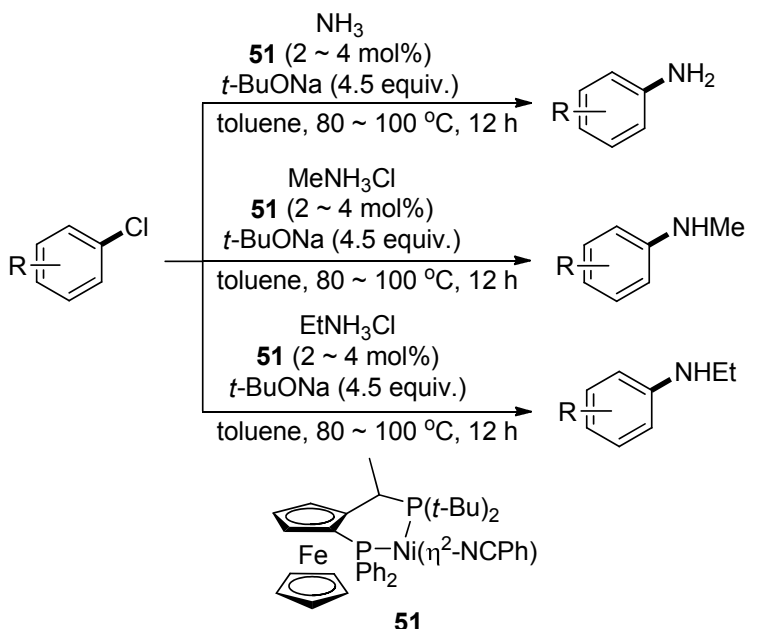

图式 20 二茂铁基镍配合物催化的芳基氯与氨或铵盐的氨基 化反应

Scheme 20 Ferrocenyl-nickel complexes-catalyzed amination of aryl chlorides with ammonia or ammonium salts
联得到伯胺、仲胺的衍生物. 在该催化剂作用下，硫 酸铵等多种铵盐也可代替氨气作为胺化试剂与芳基 卤发生氨基化反应得到相应的伯胺或仲胺衍生物, 扩展了该类反应底物的适用范围，同时发展了一些 难以用常规方法制备的复杂有机胺类化合物的合成 方法，有望在工业上得到广泛应用。

Stradiotto 等 ${ }^{[53]}$ 报道了 JosiPhos $(\mathbf{5 2}) /\left[\mathrm{Ni}(\operatorname{cod})_{2}\right]$ 催化 体系催化的芳基卤或芳基甲苯磺酸盐的氨基化反应(Eq. 22). 研究结果表明，该催化体系对底物的适用范围非 常广，无论是芳基或杂芳基的氯化物、溴化物，还是芳 基或杂芳基的对甲苯磺酰化合物均适用于该反应，且芳 基上取代基的适用范围也很广，即使芳环上连有强供电 子基(如甲氧基)、强吸电子基(如氰基、三氟甲基等)或 连有杂芳基(如吡咯基、吡啶基等)均能以较高产率得到 相应的氨基化产物. 该反应具有底物适用范围广、配体 价廉易得、实验操作简单等特点.

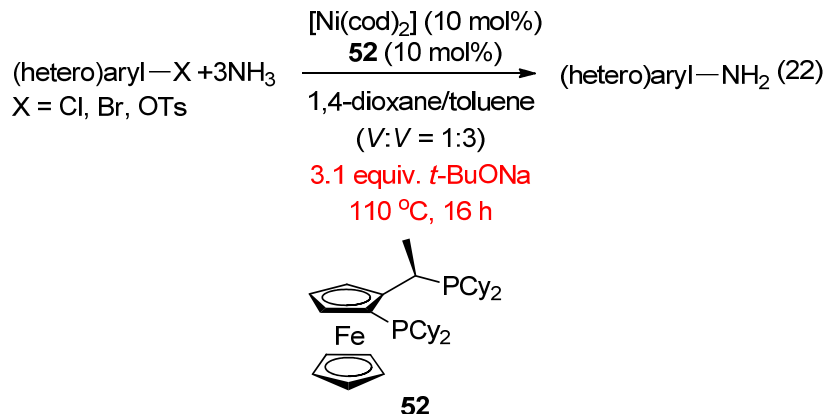

\section{3 偶联反应}

交叉偶联反应是一类用于碳碳键形成的重要化学 反应，在有机合成中应用十分广泛 ${ }^{[54]}$. 近年来，我们课 题组研究发现二茂铁异噁唑(啉)配体与钯催化剂在催化 Heck 及卤代烃和炔的交叉偶联反应中显示了较高的催 化活性及选择性(Eq. 23). 由芳香二醛出发设计合成了 几种双二茂铁双异啞唑(啉)钯配合物 53, 并将其应用于 Heck 及卤代烃和炔的交叉偶联反应中 ${ }^{[55 ~ 57]}$. 结果表明, 这种双二茂铁双异噁唑(啉)钯配合物稳定性高, 催化活 性及选择性均较好，催化 Heck 及卤代烃和炔的交叉偶 联反应时可在水溶剂中进行, 无需惰性气体保护和添加 其他含磷配体或铜催化剂，且催化 Heck 偶联反应中得

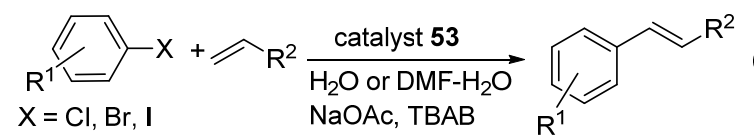


到的烯烃以 $E$-式构型为主. 该催化体系的优点是可使 用无毒无害的水作溶剂, 而且催化剂可通过过滤的方式 进行回收和循环使用.

2012 年, Deng 等 ${ }^{[58]}$ 报道了一种双 $N$-杂环卡宾双核 铁配合物 $\left[\left(\mathrm{IPr}_{2} \mathrm{Me}_{2}\right) \mathrm{Fe}\left(\mu_{2}-\mathrm{NDipp}\right)_{2} \mathrm{Fe}\left(\mathrm{IPr}_{2} \mathrm{Me}_{2}\right)\right]$ (54)催化 的非活性的烷基氟化物与芳基格氏试剂的交叉偶联反 应(Eq. 24). 这是首例报道的铁配合物催化的有机氟化 物作为亲电体的交叉偶联反应, 该催化剂催化的 $\mathrm{C}\left(\mathrm{sp}^{3}\right)-\mathrm{F}$ 的烷基化反应对底物的普适性很好, 适用于 各种取代基的芳基格氏试剂和末端取代的烷基氟化物. 该反应经历自由基历程, 这是目前首次报道的铁配合物 催化的自由基型交叉偶联反应, 进一步拓展了铁配合物 催化的有机反应类型.

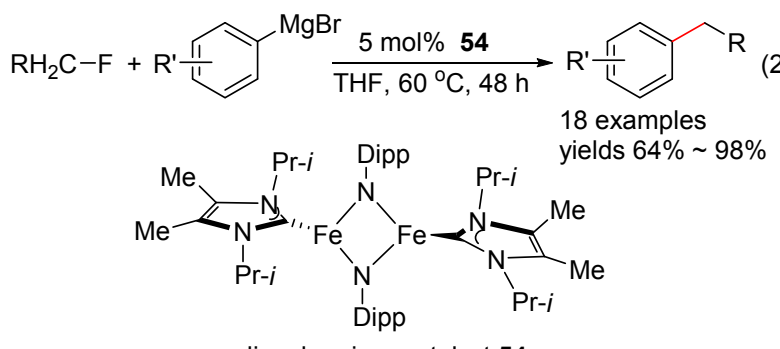

dinuclear iron catalyst 54

2015 年, $\mathrm{Hu}$ 等 ${ }^{[59]}$ 设计合成了一种双噁唑啉苯胺 (Bopa) 手性铁配合物催化剂 57, 该配合物中双噁唑啉配 体可以稳定具有催化活性中心的铁原子, 同时将该配合 物催化剂应用于烷基卤代烃与芳基格氏试剂的烷基-芳 基 Kumada 交叉偶联反应(Scheme 21), 并对其催化机理 进行了研究. 研究结果表明, 该配合物催化剂的催化活 性较高, 反应在很短的时间内即可完成，且该催化剂对 卤代烃的适用范围较广, 一级或二级的溴代烷烃或碘代 烷烃均能很好的发生反应. 机理研究表明, 配合物中 $\left[\mathrm{Fe}(\mathrm{Bopa}-\mathrm{Ph})(\mathrm{Ph})^{2}\right]^{-}$作为氧化试剂与卤代烷先发生氧化 加成，继而与格式试剂发生反应完成芳基-烷基偶联, 该机理经自由基捕捉剂和 DFT 理论计算证实. 该工作 对深入理解铁配合物催化的烷基卤代烃的交叉偶联反 应提供了有力的理论依据和实验支撑.

以廉价易得的有机酸作为反应底物的脱羧偶联反 应作为一种新的形成碳碳键的方法受到研究者的青睐, 成为近年来的研究热点. 2013 年, Mao 等 ${ }^{[60]}$ 以二茂铁为 催化剂，肉桂酸和非活化的苄基化合物为原料，在无任 何配体存在的条件下，以二叔丁基过氧化物(DTBP)为 引发剂实现了 $\mathrm{C}\left(\mathrm{sp}^{2}\right)-\mathrm{C}\left(\mathrm{sp}^{3}\right)$ 键间的脱羧偶联反应 $(\mathrm{Eq}$. $25)$, 该反应的显著特点使用价廉易得且性质稳定的非 活化的苯甲基化合物作为底物可有效避免使用对金属 偶联反应敏感的底物, 且该反应兼具底物适用范围广, 官能团兼容性好等优点.

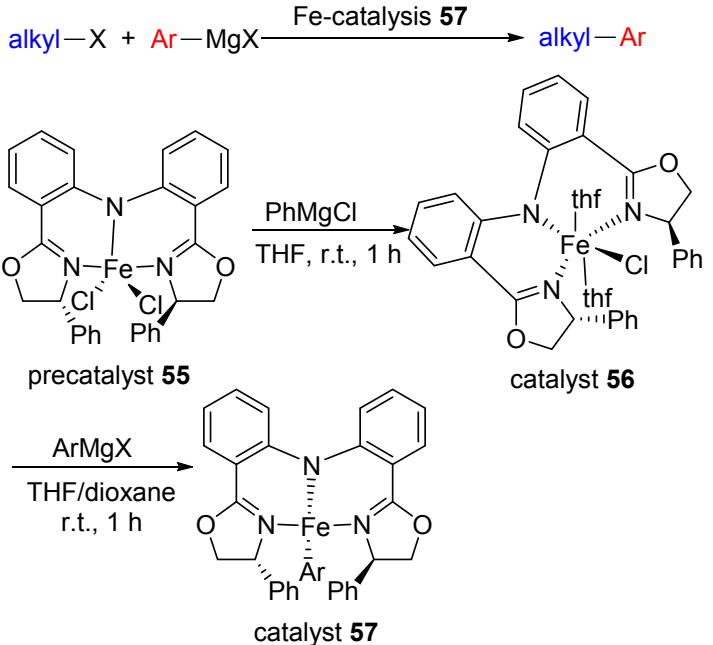

图式 21 双噁唑啉苯胺基钳形铁配合物催化的烷基-芳基 Kumada 偶联反应

Scheme 21 Bis(oxazolinylphenyl)amido pincer iron complexes catalyzed the alkyl-aryl Kumada coupling reactions

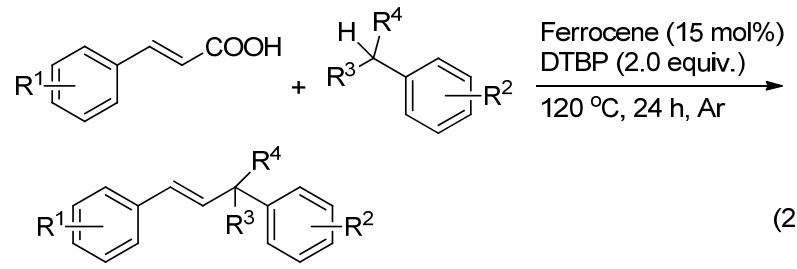

\section{$6.4 \mathrm{~N}$-甲基化反应}

碳酸二甲酯(DMC)作为一种绿色化学试剂，困其分 子中含有多种活泼的官能团，可取代卤代甲烷、硫酸二 甲酯等甲基化试剂被广泛应用于有机合成中. 近年来碳 酸二甲酯(DMC)作为甲基化试剂与相应化合物发生甲 基化反应备受关注，成为有机合成领域研究的热点之 一. 2014 年, Sortais 等 ${ }^{[61]}$ 报道了 $N$-杂环卡宾铁配合物催 化仲胺与碳酸二甲酯或碳酸二乙酯的 $N$-甲基化反应 (Eq. 26). 该反应以配合物 $\left[\mathrm{CpFe}(\mathrm{CO})_{2}(\mathrm{IMes})\right] \mathrm{I}$ (58)为催 化剂，苯基硅烷 $\left(\mathrm{PhSiH}_{3}\right)$ 为还原剂，光照条件下可高效 实现仲胺类化合物 $N$-甲基化合成多种叔胺衍生物。与 传统方法相比，使用该类铁配合物催化剂催化仲胺的 $N$-甲基化反应实验条件更温和，且产率有明显提高。

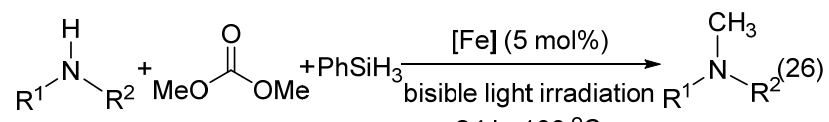
$\mathrm{R}^{1}, \mathrm{R}^{2}=$ alkyl, aryl $24 \mathrm{~h}, 100^{\circ} \mathrm{C} \quad 17$ examples yields $54 \% \sim 98 \%$ 


\section{7 结论与展望}

综上所述，新颖配体结构的铁配合物的设计合成及 其催化的有机反应是近年来配位化学研究的热点领域 之一. 从报道的许多成功例子来看，与钉、铑、钯等贵 金属配合物催化剂以及其它具有毒性的过渡金属催化 剂相比, 铁配合物催化的有机反应的研究已经取得了很 大的突破. 大量的基础研究和应用研究正在不断深入进 行, 铁配合物催化中心的本质和催化机理逐渐得到阐 明. 因此, 随着科研工作者对铁配合物催化剂结构及性 能的构效关系认识的不断加深, 新颖铁配合物催化剂的 设计合成及其在催化有机反应中的应用将得到持久和 深入的发展, 对有机金属化学、配位化学等学科的发展 也将起到至关重要的作用.

尽管铁配合物的合成及其催化性能研究已经取得 了一定进展，但是相对于一些钌、钯等贵金属配合物催 化剂的研究而言, 新颖铁配合物催化剂的开发仍然是配 合物化学研究的一个新兴的研究领域. 铁配合物催化的 有机反应仍然存在反应条件苛刻、底物普适性差等缺点. 多数铁配合物在催化苯乙酮或亚胺的氢化还原反应中 具有良好的催化活性或对映选择性, 而在其他类型的反 应中应用较少, 且个别催化剂还存在配体合成困难、价 格昂贵等问题，使得其应用受到限制. 因而设计并合成 一些制备简单、价格低廉、结构稳定、底物普适性好的 手性铁配合物催化剂是铁配合物研究领域的核心内容 之一.

未来对铁配合物催化的有机反应研究中还存在诸 多挑战，一方面烯烃不对称氢化反应及不对称交叉偶联 反应构建 $\mathrm{C}-\mathrm{C}$ 键的研究将是铁配合物催化的有机反应 面临的一大挑战. 另一方面, 认识和理解手性铁配合物 催化剂中结构及性能的关系以及催化体系中添加物对 催化反应机理的作用等方面将成为未来研究铁配合物 的另一重要研究方向. 因此, 我们相信未来铁配合物在 配体的设计开发、催化的有机反应, 尤其是不对称催化 等方面都将有着更加广阔的发展前景.

\section{References}

[1] Reppe, W. Experientia 1949, 5, 93.

[2] Kealy, T. J.; Pauson, P. L. Nature 1951, 168, 1039.

[3] Hieber, V. W.; Braun, G. Z. Naturforsch. 1959, 146, 132.

[4] Bolm, C.; Legros, J.; Le Paih, J.; Zani, L. Chem. Rev. 2004, 104, 6217.

[5] (a) Rose, E.; Andrioletti, B.; Zrig, S.; Quelquejeu-Ethève, M. Chem. Soc. Rev. 2005, 34, 573.

(b) Correa, A.; García Mancheño, O.; Bolm, C. Chem. Soc. Rev. 2008, 37, 1108 .

(c) Sun, C.-L.; Li, B.-J.; Shi, Z.-J. Chem. Rev. 2011, 111, 1293.

(d) Gopalaiah, K. Chem. Rev. 2013, 113, 3248.

[6] (a) Plietker, B. Iron Catalysis in Organic Chemistry: Reactions and
Applications, Wiley-VCH, Weinheim, Germany, 2008.

(b) Plietker, B. Topics in Organometallic Chemsitry, Iron Catalysis: Fundamentals and Applications, Springer-VBH, Berlin, 2011, Vol. 33.

[7] Gan, K.; Sadeer, A.; Xu, C.; Li, Y.; Pullarkat, S. A. Organometallics 2014, 33, 5074.

[8] (a) Champouret, Y. D. M.; Fawcett, J.; Nodes, W. J.; Singh, K.; Solan, G. A. Inorg. Chem. 2006, 45, 9890.

(b) Sun, W.-H.; Hao, P.; Zhang, S.; Shi, Q.; Zuo, W.; Tang, X.; Lu, X. Organometallics 2007, 26, 2720.

[9] (a) Ma, J.; Feng, C.; Wang, S.; Zhao, K.-Q.; Sun, W.-H.; Redshaw, C.; Solan, G. A. Inorg. Chem. Front. 2014, 1, 14.

(b) Searles, K.; Fortier, S.; Khusniyarov, M. M.; Carroll, P. J.; Sutter, J.; Meyer, K.; Mindiola, D. J.; Caulton, K. G. Angew. Chem., Int. Ed. 2014, 53, 14139.

(c) Lin, Y.-F.; Ichihara, N.; Nakajima, Y.; Ozawa, F. Organometallics 2014, 33, 6700.

(d) Suzuki, T.; Matsumoto, J.; Kajita, Y.; Inomata, T.; Ozawaa, T.; Masuda, H. Dalton Trans. 2015, 44, 1017.

[10] (a) Zuo, W.; Tauer, S.; Prokopchuk, D. E.; Morris, R. H. Organometallics 2014, 33, 5791.

(b) Cussó, O.; Garcia-Bosch, I.; Ribas, X.; Lloret-Fillol, J.; Costas, M. J. Am. Chem. Soc. 2013, 135, 14871.

[11] (a) Zhang, Q.; Xiang, L.; Deng, L. Organometallics 2012, 31, 4537. (b) Gallego, D.; Inoue, S.; Blom, B.; Driess, M. Organometallics 2014, 33, 6885 .

(c) Bhattacharya, P.; Krause, J. A.; Guan, H. Organometallics 2014, 33, 6113.

[12] Karpiniec, S. S.; McGuinness, D. S.; Britovsek, G. J. P.; Wierengaa, T. S.; Patel, J. Chem. Commun. 2011, 47, 6945.

[13] Xing, Q.; Zhao, T.; Qiao, Y.; Wang, L.; Redshaw, C.; Sun, W.-H. RSC Adv. 2013, 3, 26184.

[14] Huang, F.; Xing, Q.; Liang, T.; Flisak, Z.; Ye, B.; Hu, X.; Yang, W.; Sun, W.-H. Dalton Trans. 2014, 43, 16818.

[15] Chen, J.; Xi, T.; Lu, Z. Org. Lett. 2014, 16, 6452.

[16] Chen, J.; Cheng, B.; Cao, M.; Lu, Z. Angew. Chem., Int. Ed. 2015, 54,4661 .

[17] Morris, R. H. Chem. Soc. Rev. 2009, 38, 2282.

[18] Bhattacharya, P.; Krause, J. A.; Guan, H. Organometallics 2014, $33,6113$.

[19] Zuo, Z.; Zhang, L.; Leng, X.; Huang, Z. Chem. Commun. 2015, 51, 5073.

[20] Bleith, T.; Wadepohl, H.; Gade, L. H. J. Am. Chem. Soc. 2015, 137, 2456.

[21] Ito, J.; Hosokawa, S.; Khalid, H. B.; Nishiyama, H. Organometallics 2015, 34, 1377.

[22] Zuo, Z.; Sun, H.; Wang, L.; Li, X. Dalton Trans. 2014, 43, 11716.

[23] (a) Wu, S.; Li, X.; Xiong, Z.; Xu, W.; Lu, Y.; Sun, H. Organometallics 2013, 32, 3227.

(b) Zhao, H.; Sun, H.; Li, X. Organometallics 2014, 33, 3535.

[24] Huang, S.; Zhao, H.; Li, X.; Wang, L.; Sun, H. RSC Adv. 2015, 5, 15660 .

[25] Wang, L.; Sun, H.; Li, X. Eur. J. Inorg. Chem. 2015, 2732.

[26] Xue, B.; Sun, H.; Li, X. RSC Adv. 2015, 5, 52000.

[27] Zhang, C.; Yu, S.-B.; Hu, X.-P.; Wang, D.-Y.; Zheng, Z. Org. Lett. 2010, 12,5542 .

[28] Check, C. T.; Jang, K. P.; Schwamb, C. B.; Wong, A. S.; Wang, M. H.; Scheidt, K. A. Angew. Chem., Int. Ed. 2015, 54, 4264.

[29] Zhang, C.; Hu, X.-H.; Wang, Y.-H.; Zheng, Z.; Xu, J.; Hu, X.-P. J. Am. Chem. Soc. 2012, 134, 9585.

[30] Casitas, A.; Krause, H.; Goddard, R.; Fürstner, A. Angew. Chem., Int. Ed. 2015, 54, 1521. 
[31] Cussó, O.; Ribas, X.; Lloret-Fillol, J.; Costas, M. Angew. Chem., Int. Ed. 2015, 54, 2729.

[32] Chatterjee, S.; Paine, T. K. Inorg. Chem. 2015, 54, 1720.

[33] (a) Li, Y.; Yu, S.; Wu, X.; Xiao, J.; Shen, W.; Dong, Z.; Gao, J. J. Am. Chem. Soc. 2014, 136, 4031.

(b) Li, Y.; Yu, S.; Shen, W.; Gao. J. Acc. Chem. Res. 2015, 48, 2587.

(c) Yoshimura, M.; Tanaka, S.; Kitamura, M. Tetrahedron Lett. 2014, 55, 3635 .

(d) Foubelo, F.; Nájera, C.; Yus, M. Tetrahedron: Asymmetry 2015, 26,769 .

[34] (a) Mikhailine, A. A.; Morris, R. H. Inorg. Chem. 2010, 49, 11039. (b) Lagaditis, P. O.; Lough, A. J.; Morris, R. H. Inorg. Chem. 2010, 49, 10057.

(c) Meyer, N.; Lough, A. J.; Morris, R. H. Chem. Eur. J. 2009, 15, 5605 .

(d) Mikhailine, A.; Lough, A. J.; Morris, R. J. Am. Chem. Soc. 2009, 131, 1394.

(e) Sui-Seng, C.; Freutel, F.; Lough, A. J.; Morris, R. Angew. Chem., Int. Ed. 2008, 47, 940.

[35] Sues, P. E.; Lough, A. J.; Morris, R. H. Organometallics 2011, 30, 4418.

[36] Mikhailine, A. A.; Maishan, M. I.; Lough, A. J.; Morris, R. H. J. Am. Chem. Soc. 2012, 134, 12266.

[37] Prokopchuk, D. E.; Sonnenberg, J. F.; Meyer, N.; Iuliis, M. Z.-D.; Lough, A. J.; Morris, R. H. Organometallics 2012, 31, 3056.

[38] Zuo, W.; Lough, A. J.; Li, Y. F.; Morris, R. H. Science 2013, 342, 1080.

[39] Prokopchuk, D. E.; Morris, R. H. Organometallics 2012, 31, 7375.

[40] Zuo, W.; Tauer, S.; Prokopchuk, D. E.; Morris, R. H. Organometallics 2014, 33, 5791.

[41] Sonnenberg, J. F.; Lough, A. J.; Morris, R. H. Organometallics 2014, 33, 6452.

[42] Lagaditis, P. O.; Sues, P. E.; Sonnenberg, J. F.; Wan, K. Y.; Lough, A. J.; Morris, R. H. J. Am. Chem. Soc. 2014, 136, 1367.

[43] Zuo, W.; Morris, R. H. Nat. Protoc. 2015, 10, 241.

[44] Smith, S. A. M.; Morris, R. H. Sythesis 2015, 47, 1775.
[45] Bigler, R.; Mezzetti, A. Org. Lett. 2014, 16, 6460.

[46] Mikhailine, A. A.; Maishan, M. I.; Morris, R. H. Org. Lett. 2012, 14, 4638.

[47] Mazza, S.; Scopelliti, R.; Hu, X. Organometallics 2015, 34, 1538.

[48] Kuwano, R.; Hashiguchi, Y.; Ikeda, R.; Ishizuka, K. Angew. Chem., Int. Ed. 2015, 54, 2393.

[49] Gan, K.; Sadeer, A.; Xu, C.; Li, Y.; Pullarkat, S. A. Organometallics 2014, 33, 5074.

[50] Hellmuth, T.; Frey, W.; Peters, R. Angew. Chem., Int. Ed. 2015, 54, 2788.

[51] Foo, K.; Sella, E.; Thomé, I.; Eastgate, M. D.; Baran, P. S. J. Am. Chem. Soc. 2014, 136, 5279.

[52] Green, R. A.; Hartwig, J. F. Angew. Chem., Int. Ed. 2015, 54, 3768.

[53] Borzenko, A.; Rotta-Loria, N. L.; MacQueen, P. M.; Lavoie, C. M.; McDonald, R.; Stradiotto, M. Angew. Chem., Int. Ed. 2015, 54, 3773.

[54] (a) Yeung, C. S.; Dong, V. M. Chem. Rev. 2011, 111, 1215.

(b) Jana, R.; Pathak, T. P.; Sigman, M. S. Chem. Rev. 2011, 111, 1417.

(c) Cherney, A. H.; Kadunce, N. T.; Reisman, S. E. Chem. Rev. 2015, 115, 9587 .

(d) Liu, C.; Yuan, J.; Gao, M.; Tang, S.; Li, W.; Shi, R.; Lei, A. Chem. Rev. 2015, 115, 12138.

[55] Shang, Y.-J.; Wu, J.-W.; Fan, C.-L.; Hu, J.-S.; Lu, B.-Y. J. Organomet. Chem. 2008, 693, 2963.

[56] Feng, Z.-J.; Yu, S.-Y.; Shang, Y.-J. Appl. Organomet. Chem. 2008, 22, 577.

[57] Yu, S.-Y.; Zhang, Z.-Q.; Yu, Z.-Y.; Shang, Y.-J. Appl. Organomet. Chem. 2014, 28, 657.

[58] Mo, Z.; Zhang, Q.; Deng, L. Organometallics 2012, 31, 6518.

[59] Bauer, G.; Wodrich, M. D.; Scopelliti, R.; Hu, X. Organometallics 2015, 34, 289.

[60] Yang, H.; Yan, H.; Sun, P.; Zhu, Y.; Lu, L.; Liu, D.; Rong, G.; Mao, J. Green Chem. 2013, 15, 976.

[61] Zheng, J.; Darcel, C.; Sortais, J.-B. Chem. Commun. 2014, 50, 14229. 